\title{
Mixed convection heat transfer of turbulent flow in a three- dimensional lid-driven cavity with a rotating cylinder
}

\author{
Ali Khaleel Kareem ${ }^{\text {a, b,*, }}$, Shian Gao ${ }^{\text {a }}$ \\ ${ }^{a}$ Department of Engineering, University of Leicester, Leicester LE1 7RH, United Kingdom \\ ${ }^{\mathrm{b}}$ Engineering Department, University of Thi-Qar, 64001 Nassiriya, Iraq
}

\begin{abstract}
A numerical study has been carried out to investigate the combined forced and natural convection heat transfer in a differentially heated $3 D$ obstructed cavity with a thermally insulated rotating circular cylinder. The cavity has a hot stationary bottom wall and a cold top lid-driven wall, and all the other walls completing the domain are motionless and adiabatic. The simulations are performed for different Reynolds numbers, Re =5000, 10000, 15000 and 30000, and for dimensionless rotational speeds of the cylinder, $0 \leq \Omega \leq 10$. The performance of two turbulence methods, Large Eddy Simulation (LES) and Unsteady Reynolds-Averaged Navier-Stokes (URANS), has been evaluated in this research. The flow and thermal fields are studied through flow vectors, isotherm contours and iso-surfaces temperature, as well as through the average Nusselt number $\left(N u_{a v}\right)$ and velocity components. The results demonstrate clearly that the flow patterns and the thermal fields are influenced strongly by increasing either the rotating cylinder speed or the Reynolds number. Furthermore, both LES and URANS solutions can capture the essential feature of the primary eddies in the cavity. But this study has shown convincing evidence that only the LES method can predict the structure details of the secondary eddies that have profound effects on the heat transfer behaviour within the enclosure.
\end{abstract}

Keywords: Rotating cylinder, Lid-driven cavity, Mixed convection, Turbulent flow, URANS, LES.

\footnotetext{
*Corresponding author at: Department of Engineering, University of Leicester, Leicester LE1 7RH, United Kingdom. Tel: +44 (0)116 252 2874; fax: +44 (0)116 2522525.
}

Email address: akkak2@1e.ac.uk, alikhaleel17@yahoo.com (A.K. Kareem). 


\section{Introduction}

32 Over the last few decades, the numerical simulations of turbulent flows and heat transfer have become one of the essential attentions of engineering applications in the industrial and engineering fields. Indeed, for high value Reynolds number turbulent flows, the expanded scope of turbulent vortices has gained major interests. Large Eddy Simulation (LES) method is increasingly involved in predicting the detailed turbulent flow scales [1, 2], though the Reynolds Averaged Navier-Stokes (RANS) approach is still a useful tool in evaluating the time averaged features of the turbulent flows [3-6]. Even though the LES costs more computational

\begin{tabular}{|c|c|c|c|}
\hline \multicolumn{4}{|c|}{ Nomenclature } \\
\hline CFL & $\begin{array}{l}\text { Courant-Friedrichs-Lewy } \\
\text { number }\end{array}$ & $\mathrm{Y}$ & $\begin{array}{l}\text { distance along the non- } \\
\text { dimensional } y \text {-coordinate }(y / H)\end{array}$ \\
\hline $\mathrm{D}$ & width of the cavity on z-axis (m) & $\mathrm{Z}$ & distance along the non- \\
\hline $\mathrm{d}$ & cylinder diameter (m) & & dimensional z-coordinate (z/D) \\
\hline FVM & finite volume method & & \\
\hline Gr & Grashof number $\left(\mathrm{g} \beta_{\mathrm{m}} \Delta \mathrm{TW} \mathrm{W}^{3} / \mathrm{v}_{\mathrm{m}}^{2}\right)$ & \multicolumn{2}{|c|}{ Greek symbols } \\
\hline $\mathrm{h}$ & $\begin{array}{l}\text { convective heat transfer } \\
\text { coefficient }\left(\mathrm{W} / \mathrm{m}^{2} \mathrm{~K}\right)\end{array}$ & $\alpha$ & $\begin{array}{l}\text { thermal diffusivity of the fluid } \\
\left(\mathrm{m}^{2} / \mathrm{s}\right)\end{array}$ \\
\hline $\mathrm{k}$ & turbulent kinetic energy $\left(\mathrm{m}^{2} / \mathrm{s}^{2}\right)$ & $\beta$ & volumetric coefficient of thermal \\
\hline $\mathrm{L}$ & width of the cavity on $\mathrm{x}$-axis (m) & & expansion $(1 / K)$ \\
\hline $\mathrm{Nu}$ & Nusselt number & $\mu$ & dynamic viscosity of the fluid \\
\hline $\operatorname{Pr}$ & Prandtl number $\left(v_{\mathrm{m}} / \alpha_{\mathrm{m}}\right)$ & & $(\mathrm{Pa} / \mathrm{s})$ \\
\hline $\mathrm{Ra}$ & Rayleigh number (Gr Pr) & $v$ & kinematic viscosity of the fluid \\
\hline $\mathrm{Re}$ & Reynolds number $\left(\mathrm{U}_{0, \mathrm{~m}} \mathrm{~W} / \mathrm{v}_{\mathrm{m}}\right)$ & & $\left(\mathrm{m}^{2} / \mathrm{s}\right)$ \\
\hline $\mathrm{Ri}$ & Richardson number $\left(\mathrm{Gr} / \mathrm{Re}^{2}\right)$ & $v_{s g s}$ & sub-grid scale (SGS) viscosity \\
\hline$\overline{\mathrm{S}}_{\mathrm{ij}}$ & large-scale strain rate tensor for & $\rho$ & density of the fluid $\left(\mathrm{kg} / \mathrm{m}^{3}\right)$ \\
\hline $\mathrm{T}$ & $\begin{array}{l}\text { grid-filter } \\
\text { temperature of the fluid }(\mathrm{K})\end{array}$ & $\varepsilon$ & $\begin{array}{l}\text { dissipation rate of turbulent } \\
\text { kinetic energy }\left(\mathrm{m}^{2} / \mathrm{s}^{3}\right)\end{array}$ \\
\hline $\mathrm{t}$ & time & $\delta_{i j}$ & Kronecker's delta \\
\hline $\mathrm{u}$ & velocity component at $\mathrm{x}$-direction & $\bar{\Delta}$ & grid-filter width \\
\hline $\mathrm{U}$ & $\begin{array}{l}(\mathrm{m} / \mathrm{s}) \\
\text { dimensionless velocity }\end{array}$ & $\begin{array}{l}\tau_{i j} \\
\omega\end{array}$ & $\begin{array}{l}\text { subgrid-scale }(\mathrm{SGS}) \text { stress tensor } \\
\text { rotational speed }(\mathrm{rad} / \mathrm{s})\end{array}$ \\
\hline $\mathrm{U}_{0}$ & $\begin{array}{l}\text { component at } \mathrm{x} \text {-direction } \\
\text { lid velocity }(\mathrm{m} / \mathrm{s})\end{array}$ & $\Omega$ & dimensionless rotational speed \\
\hline $\mathrm{v}$ & velocity component at $y$-direction & Subs & \\
\hline V & dimensionless velocity & $\begin{array}{l}\text { av } \\
\mathrm{b}\end{array}$ & $\begin{array}{l}\text { average value } \\
\text { buoyancy }\end{array}$ \\
\hline W & $\begin{array}{l}\text { component at y-direction } \\
\text { dimensionless velocity }\end{array}$ & $\begin{array}{l}\mathrm{C} \\
\mathrm{H}\end{array}$ & $\begin{array}{l}\text { value of cold temperature } \\
\text { value of hot temperature }\end{array}$ \\
\hline$x$ & $\begin{array}{l}\text { component at } \mathrm{z} \text {-direction } \\
\text { distance along the } \mathrm{x} \text {-coordinate }\end{array}$ & $\mathrm{rms}$ & root mean square \\
\hline $\begin{array}{l}x \\
X\end{array}$ & $\begin{array}{l}\text { distance along the non- } \\
\text { dimensional } \mathrm{x} \text {-coordinate }(\mathrm{x} / \mathrm{L})\end{array}$ & $\begin{array}{l}\text { sgs } \\
t\end{array}$ & $\begin{array}{l}\text { sub-grid scale } \\
\text { turbulent }\end{array}$ \\
\hline
\end{tabular}


resources than the RANS modelling, this method performs better in terms of data availability and accuracy [7].

The effect of combined natural convection, which emerges as a sequence of buoyancy effects, with forced convection, which occurs as a result of the fluid motion due to shear forces that are offered by external means such as the partial physical motion of the domain, is defined as mixed convection. There have been quite a few studies over the last few years on heat convection problems in the $2 \mathrm{D}$ cavities containing either a rotating or stationary cylinder with different dimensionless diameters and boundary conditions. A 2D combined convection heat transfer of heated top lid-driven wall cavity that has an internal central circular cylinder and heater was simulated by Ray and Chatterjee [8]. It was demonstrated that the internal circular objects lead to a considerable increment in the Nusselt number $(\mathrm{Nu})$. A study of mixed and natural convection of stationary and rotating centred cylinder in a 2D square cavity, with different rotating speeds, was carried out by Liao and Lin [9]. It was concluded that by reducing the Richardson number $(\mathrm{Ri})$ the mean value of Nusselt number $\left(\mathrm{Nu}_{\text {mean }}\right)$ decreases. Heat transfer was enhanced by using small aspect ratio between the inner cylinder and the outer cavity which leads to generating a greater $\mathrm{Nu}$. Hydro-magnetic mixed convection heat transfer in a $2 \mathrm{D}$ moving wall cavity with central rotating conducting solid cylinder was demonstrated numerically by Chatterjee, et al. [10]. It was summarised that an increase in rotation of the conductive cylinder generates the enhancement of the heat transfer within the cavity.

Hussain and Hussein [11] numerically simulated laminar steady state mixed convection of air within differentially heated cavity containing conductive rotating cylinder. It can be pointed out that when the forced convection dominates, major vortices were founded around the cylinder. No influences were noticed on both the flow and thermal fields when changing the cylinder location at equal domination between the natural and forced convection. A natural convection of a 2D square cavity with cold and hot cylinders was numerically investigated by Park, et al. [12]. Different locations of cold and hot cylinders were the main concern. The outcome showed that when the surfaces of the cylinders and the cavity were close to each other the Nusselt number increases. An unsteady natural convection of two heated horizontal rotating cylinders that erected within a $2 \mathrm{D}$ closed square cavity was simulated by Karimi, et al. [13]. It was observed that at a low Rayleigh number ( $\mathrm{Ra}$ ) (less than $10^{4}$ ) the distance between the cylinders has a clear effect on the averaged-area of the Nusselt number. When the Rayleigh number is higher than $10^{4}$ and no more than $10^{7}$, the influence of spacing between the circular cylinders could be ignored. A study of 2D natural convection in a closed square cavity with two horizontal 
inner cylinders was numerically carried out by Yoon, et al. [14]. The upper cylinder was cooled, while the lower one was heated. The lower and upper half of the cavity was the place of the equidiameter cylinders. It was concluded that an increase in the radius of the cylinders at all values of the Rayleigh number drives the increment of the heat transfer rate and dominates the cold upper circular cylinder on a wider area.

An inner sinusoidally heated circular cylinder placed in a cavity was involved in a study of a 2D numerical unsteady natural convection heat transfer by Roslan, et al. [15]. It can be pointed out that the flow field has two inner vortices and a heated cylinder provided a warm-chamber, which impacts on the heat transfer. Although the heat transfer was not changed by changing cylinder radius at the lowest value of the parameters, temporal increasing in the heat transfer was found by increasing the cylinder radius to the maximum value of the dimensionless parameters. In addition, it was observed that oscillating heat source of the cylinder caused augment in the heat transfer rate. A natural convection of circular cylinder within a 2D rhombus enclosure filled by water was numerically observed by Choi, et al. [16]. It was noticed that the thermal features of the heat transfer between the cavity and its cylinder stick in accordance with the value of the Rayleigh number and the cylinder location. Increasing Rayleigh number would therefore lead to an increment in the Nusselt number for both the enclosure and its cylinder. In addition, when the cylinder is located on the bottom wall of the rhombus cavity, the Nusselt numbers for both the enclosure and its cylinder reach the maximum values. The lowest value of the Nusselt numbers occurred when the cylinder was nearby the inner top of the cavity. The investigations of mixed and natural convection of stationary and rotating with different rotating speeds centred cylinder in a 2D square cavity study were carried out by Liao and Lin [9]. It was figured out that a reduction in the Nusselt number happens when decreasing the Richardson number. Heat transfer was enhanced by using the small aspect ratio that generates a greater Nusselt number. The research of a heated hollow cylinder within the middle of the moving wall enclosure was completed by Billah, et al. [17] at different range parameters, including the size diameter of the cylinder, the Richardson number and the thermal conductivity of the fluid. The sequences of installation cylinder on the mixed convection heat transfer coefficient were mainly targeted. It has been noticed that a significant influence of the cylinder on the heat transfer ratio as well as on the cylinder diameter size occurred. Khanafer and Aithal [18] evaluated a laminar combined convection heat transfer and flow patterns of moving wall cavity that has a central cylinder. It was concluded that the heat transfer fields can be controlled by the cylinder body within the cavity. The obstacle size and location can affect the heat transfer and flow 
characteristics. Laminar mixed convection of a heated square blockage within moving wall enclosure was studied numerically by Islam, et al. [19] in order to understand the effects of the central and eccentric locations of the square body at different sizes as well as the constant Reynolds number on the heat transfer and flow patterns. It was observed that at the domination of the forced convection there were no clear differences in the heat transfer when changing either the location or the size of the installed body. An obvious influence was noticed on the Nusselt number when the natural convection was controlling the domain.

112 A combined convection heat transfer of nanofluid in a $2 \mathrm{D}$ moving wall square cavity that 113 contains a rotating cylinder was studied numerically by Selimefendigil and Öztop [20]. It was 114 demonstrated that by increasing $\mathrm{Ri}$, an increment of the heat transfer would occur. However, 115 by increasing the value of the Hartmann number the heat transfer reduces. The rotation of the 116 cylinder has a remarkable influence on the heat transfer enhancement. A 2D mixed convective transport was investigated numerically by Chatterjee, et al. [21] in a moving top wall cavity that includes a thermal adiabatic central rotating circular cylinder and this enclosure was filled by $\mathrm{Cu}$-water nanofluid. It was observed that the forced convection was dominated by fluid and the heat transfer at the low value of the Ri number. By contrast, the natural convection has the main effect on the heat transfer and fluid at a high Ri number. The drag coefficient of the moving lid-driven wall incremented by increasing the speed of the rotating cylinder and by increasing the Ri number. Thus, increasing Ri enhances the Nusselt number on the heated wall. The study of both mixed convection heat transfer and flow patterns of rotating cylinder within an obstructed cavity, filled by nanofluid, is completed by Roslan, et al. [22]. It was concluded that the heat transfer can be increased due to the increment in nanoparticles concentration. Besides, the positive effect of the rotating speed on the heat distribution and the effect of the radius size of the cylinder on the fluid behaviours were reported. Combined convection of heat transfer and fluid structure of a 2D differentially heated square cavity containing a central rotating cylinder is simulated numerically by Costa and Raimundo [23] who investigated the effects of the rotating cylinder size and rotation speed. It was demonstrated that discernible influences on the heat transfer and fluid characteristics have been noticed by changing either

133 the cylinder size or its rotation speed. Overall, it can be seen from the previous work that only 134 limited investigations have been completed on the heat convection in cavities that are filled by 135 nanofluids [20-30]. These studies take into account the influences of the nanoparticles type, 136 size and concentration on the heat transfer in various cases besides the effects of the inner 137 cylinders. 
138 Recently, some interesting studies have been completed on 2D mixed convections of moving

139 walls cavities filled by nanofluids. The effects of inclined magnetic field and discrete heating

140 of double lid-driven enclosure of a 2D MHD mixed convection of nanofluid was studied by

141 Hussain, et al. [31]. Investigating the influences of inclination angles on the combined

142 convection of laminar nanofluid flow within a 2D lid-driven cavity has been achieved

143 numerically at several dimensionless parameters [32]. Inserting an isothermal square object

144 within a moving wall enclosure filled by nanofluids to study mixed convection heat transfer

145 enhancement has been numerically accomplished by Mehmood, et al. [33].

146 By considering the literature review and to the authors' best knowledge, it can be concluded

147 that only the 2D mixed convection heat transfer in a plane moving wall square cavity with

148 rotating cylinder was studied using either classic fluids or nanofluids. However, no researcher

149 has given attention to the LES modelling of the 3D mixed convection within a cubic enclosure 150 with a rotational cylinder and comparing it to the URANS modelling. Therefore, filling this gap 151 will form the main investigation objectives of this paper.

\section{2. Numerical model}

154 The schematic diagram and main geometry parameters of the cubic moving wall cavity with rotating cylinder are shown in Fig. 1. The top wall of the cubic enclosure is treated as a cold

156 moving wall, while the bottom wall is maintained at hot constant temperature. The rest walls

157 of the geometry are assumed thermally adiabatic and stationary except the central cylinder 158 which is assumed as a rotating part (anti-clockwise). 


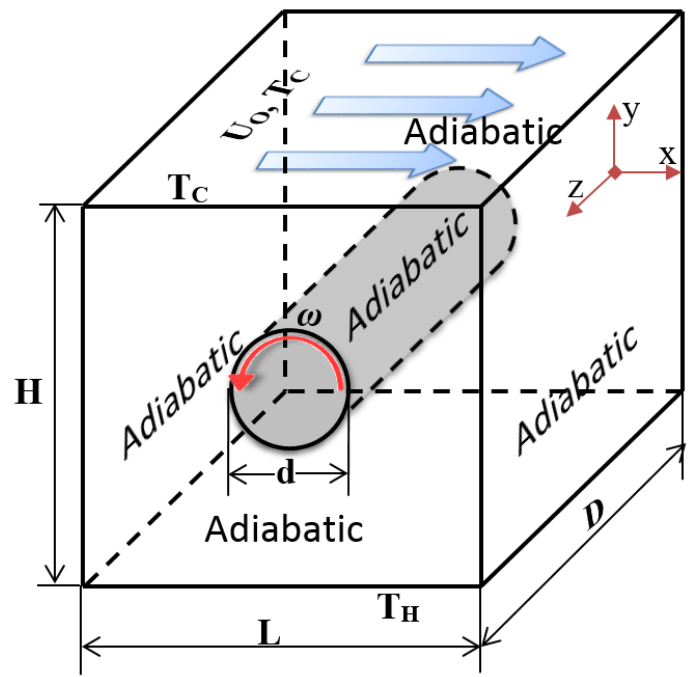

160 Fig. 1. Schematic geometry of the cubic lid-driven cavity with rotating cylinder

\subsection{Governing equations}

162 The governing equations of the continuity, momentum and energy are written below in this

163 work for three-dimensional turbulence flow and heat transfer in an incompressible Newtonian 164 fluid [34-36].

Continuity equation:

$\frac{\partial \rho}{\partial t}+\frac{\partial u_{i}}{\partial x_{i}}=0$

Momentum equation:

$\frac{\partial u_{i}}{\partial t}+\frac{\partial\left(u_{j} u_{i}\right)}{\partial x_{j}}=-\frac{\partial P}{\partial x_{i}}+\frac{1}{R e}\left(\frac{\partial^{2} u_{i}}{\partial x_{i} \partial x_{i}}\right)+\frac{G r}{R e^{2}} \theta$

Energy equation:

$\frac{\partial(\theta)}{\partial t}+\frac{\partial\left(u_{j} \theta\right)}{\partial x_{i}}=\frac{1}{R e P r}\left(\frac{\partial^{2} \theta}{\partial x_{i} \partial x_{i}}\right)$

The turbulent kinetic energy $(\mathrm{k})$ and the dissipation rate $(\varepsilon)$ are respectively shown below in equations (4) and (5) [37].

Standard k- $\varepsilon$ turbulence model: 
$\frac{\partial}{\partial t}(\rho k)+\frac{\partial}{\partial x_{i}}\left(\rho k u_{i}\right)=\frac{\partial}{\partial x_{j}}\left[\left(\mu+\frac{\mu_{t}}{\sigma_{k}}\right) \frac{\partial k}{\partial x_{j}}\right]+P_{k}+P_{b}-\rho \varepsilon+S_{k}$

$\frac{\partial}{\partial t}(\rho \varepsilon)+\frac{\partial}{\partial x_{i}}\left(\rho \varepsilon u_{i}\right)=\frac{\partial}{\partial x_{j}}\left[\left(\mu+\frac{\mu_{t}}{\sigma_{\varepsilon}}\right) \frac{\partial k}{\partial x_{j}}\right]+C_{1 \varepsilon} \frac{\epsilon}{k}\left(P_{k}+C_{3 \varepsilon} P_{b}\right)-C_{2 \varepsilon} \rho \frac{\epsilon^{2}}{k}+S_{\varepsilon}$

where $\mathrm{S}_{\mathrm{k}}$ and $\mathrm{S}_{\varepsilon}$ refer to the user-defined source terms, and $\mathrm{C}_{1 \varepsilon}, \mathrm{C}_{2 \varepsilon}$ and $\mathrm{C}_{3 \varepsilon}$ are model constants. Some other terms in the equations are defined below.

Turbulent viscosity: $\quad \mu_{t}=\rho C_{\mu} \frac{k^{2}}{\varepsilon}$

Production of $\mathrm{k}$ :

$$
P_{k}=-\rho \overline{u_{i}^{\prime} u_{j}^{\prime}} \frac{\partial u_{j}}{\partial x_{i}}
$$

Effect of buoyancy: $\quad P_{b}=\beta g_{i} \frac{\mu_{t}}{P r_{t}} \frac{\partial T}{\partial x_{i}}$

For the LES work, the sub-grid scale (SGS) model of WALE (Wall-Adapting Local Eddyviscosity) is employed, as given by Nicoud and Ducros [38] and Ben-Cheikh, et al. [7]:

$$
\mu_{t}=\rho L_{s}^{2} \frac{\left(S_{i j}^{d} S_{i j}^{d}\right)^{\frac{3}{2}}}{\left(\bar{S}_{i j} \bar{S}_{i j}\right)^{\frac{5}{2}}+\left(S_{i j}^{d} S_{i j}^{d}\right)^{\frac{5}{2}}}
$$

where $L_{s}$ and $S_{i j}^{d}$ are defined below:

$$
L_{s}=\min \left(k d, C_{W} V^{\frac{1}{3}}\right)
$$

where $C_{W}=0.325$

$$
\begin{aligned}
& S_{i j}^{d}=\frac{1}{2}\left(\bar{g}_{i j}^{2}+\bar{g}_{j i}^{2}\right)-\frac{1}{3} \delta_{i j} \bar{g}_{k k}^{2} \\
& \text { where } \bar{g}_{i j}=\frac{\partial \bar{u}_{i}}{\partial x_{j}} \\
& \bar{S}_{i j}=\frac{1}{2}\left(\frac{\partial \bar{u}_{i}}{\partial x_{j}}+\frac{\partial \bar{u}_{j}}{\partial x_{i}}\right)
\end{aligned}
$$


167 The boundary conditions for the current study are defined as:

168 Top wall:

$\partial \theta / \partial \mathrm{Y}=0, \mathrm{U}=1, \mathrm{~V}=0, \mathrm{~W}=0$

170 Bottom wall:

$171 \partial \theta / \partial \mathrm{Y}=-1, \mathrm{U}=0, \mathrm{~V}=0, \mathrm{~W}=0$

172 Other walls:

$173 \theta=0, U=0, V=0, W=0$

174 Cylinder:

175

$\omega=\frac{\Omega \times 2 U_{0}}{\mathrm{~d}}, \mathrm{~d}=0.2 \mathrm{~L}, \theta=0$

176

177

178

179

180

181

182

183

184

185

186

187

188

189

190

\subsection{Numerical procedure}

The numerical simulations of fluid flow and heat transfer were conducted by utilizing the Computational Fluid Dynamic (CFD) techniques. The finite volume method (FVM) and SIMPLEC algorithm were used to discretize the governing equations and to deal with the pressure-velocity coupling equations. The commercial code ANSYSCFLUENT (version R16.2) [39] was adapted to complete the simulations. Both steady and unsteady Reynoldsaveraged Navier-Stokes equations were solved besides the large eddy simulation method. The QUICK and implicit second order scheme were used to respectively deal with the convection and the time evaluation terms. The CFD results were collected when the convergence criteria of $10^{-5}$ were satisfied at each time step.

\section{Results and discussion}

This phase aims to understand and explore the combined impacts of the moving wall and rotating cylinder on the heat convection and flow patterns under turbulent flow conditions. The completed simulations include four Reynolds numbers, $\mathrm{Re}=5000,10000,15000$ and 30000 , and four cylinder rotation speed values, $\Omega=0,1,5$ and 10 . 


\subsection{Mesh independence test}

192 It is known that the grid independence test plays a considerable role in a CFD simulation regarding the results prediction time and accuracy. The mesh features such as density and quality were carefully considered in this study to avoid the numerical errors and to reach better computational efficiency. Structured and non-uniform cells were created in this work by Fluent ICEM 16.2 [39]. In addition, the meshes nearby the walls are refined, particularly in the area close to the circular cylinder. The generated grids of the whole domain were fine enough to capture the details of the fluid structures and thermal distribution within the cavity. Several grid numbers $(125868,292440,496800,929160$ and 1260762) were tested in order to figure out the suitable mesh number. The final chosen number of grid points in the current study was 929160 , which was proved satisfactory by different indicators that are important in order to obtain high quality results: the non-dimensional time step is 0.004 , the dimensionless wall distance $\mathrm{y}^{+} \approx 1$ and the Courant-Friedrichs-Lewy number CFL $=0.3$. Moreover, the minimum orthogonal quality is 0.7267 and the aspect ratio changes from less than 8 in the key interesting areas to 27.326 far away from the domain walls and the circular cylinder.

\subsection{Code validations}

207 The validation of the 2D rotating solid cylinder within a moving wall cavity is achieved in this 208 section. The comparison is made by using the following dimensionless parameters: $\mathrm{Gr}=10^{4}$, $209 \operatorname{Pr}=6.95,1 \leq \mathrm{Ri} \leq 10$ and $1 \leq \Omega \leq 10$. The RANS simulation findings are compared with the experimental measurements by Chatterjee, et al. [21] in terms of isotherms, streamlines contours and dimensionless velocity profiles along the vertical line at $x=0.25$. An excellent 212 agreement is accomplished as shown in Fig. 2, Fig. 3 and Fig. 4. Moreover, as shown in Fig. 5, 213 the LES prediction from the current work of a 3D lid-driven enclosure is compared to the 214 experimental outcomes of Prasad and Koseff [40] and the RANS results of Peng, et al. [41] in 215 term of mean velocity of turbulent flow. Distinctly, the current simulation results are in good agreement with those from the previous publications. Overall, the validations prove that the present simulation methods are highly reliable and accurate.
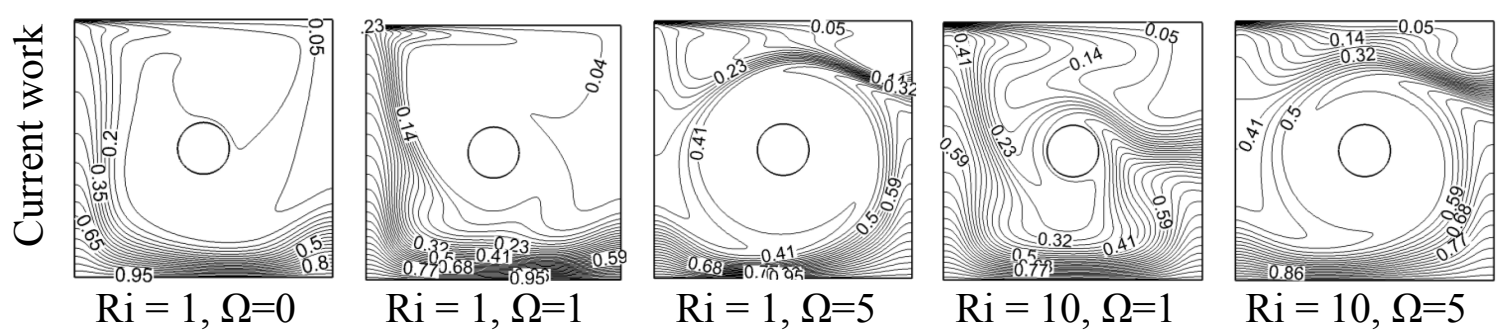


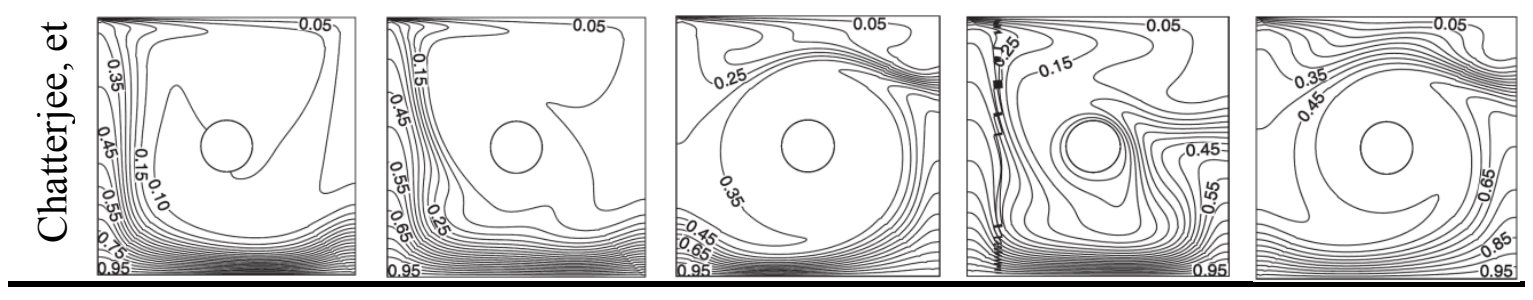

Fig. 2. Comparison of the present work of the isotherms with Chatterjee, et al. [21].

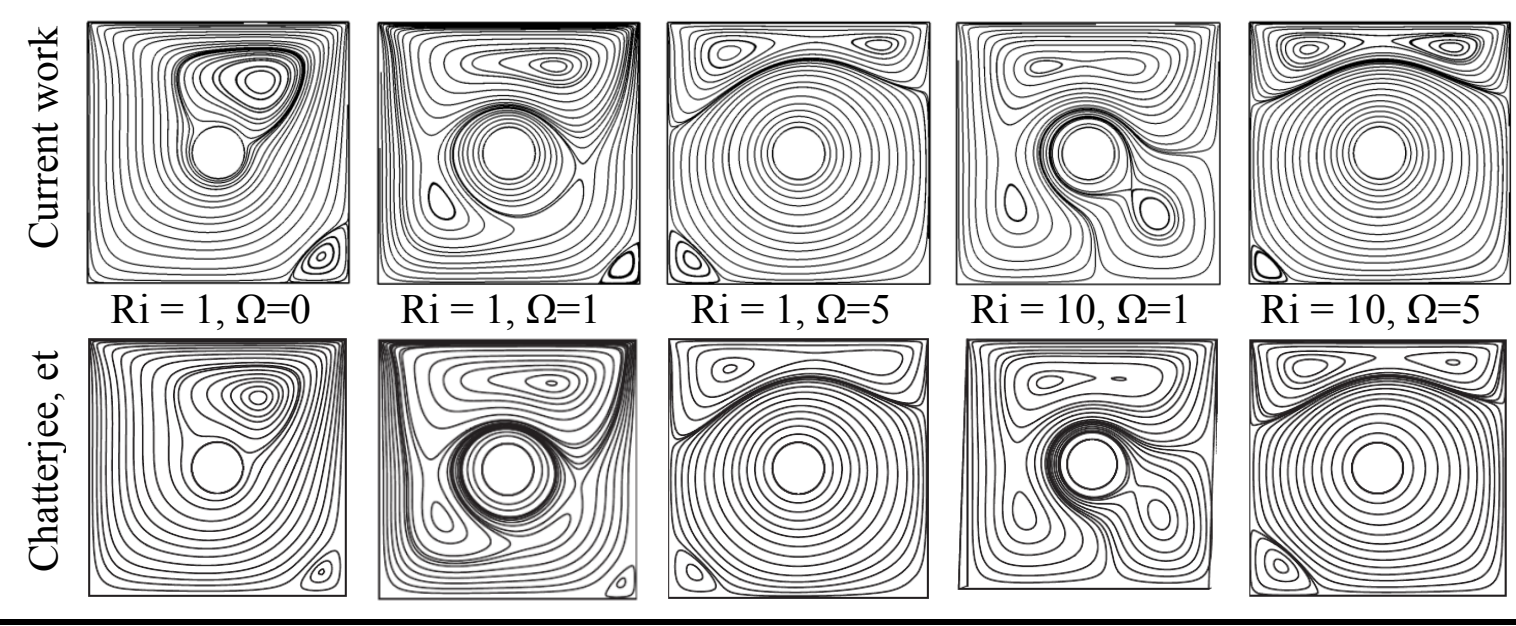

Fig. 3. Comparison of the present work of the streamlines with Chatterjee, et al. [21]. 


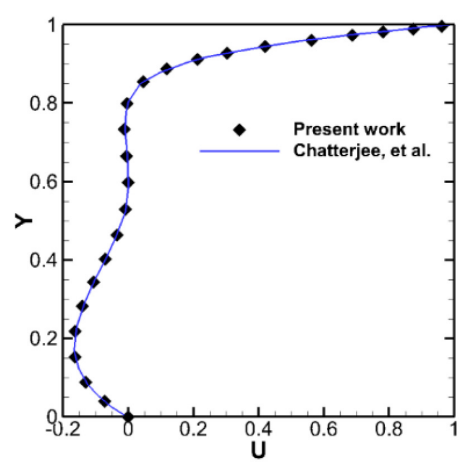

(a) $\mathrm{Ri}=1, \Omega=0$

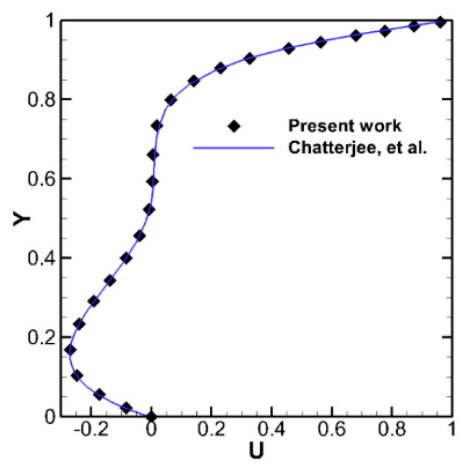

(d) $\mathrm{Ri}=5, \Omega=0$

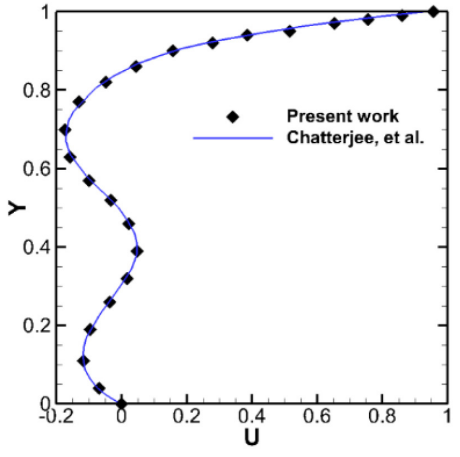

(b) $\mathrm{Ri}=1, \Omega=1$

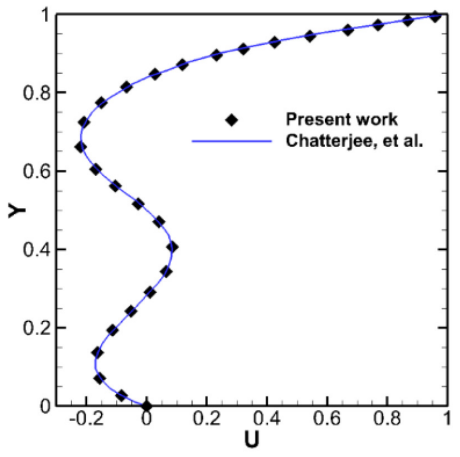

(e) $\mathrm{Ri}=5, \Omega=1$

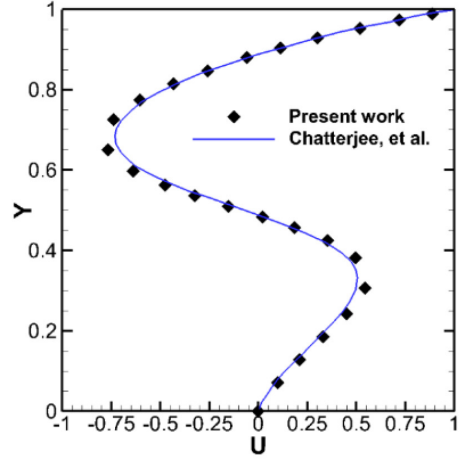

(c) $\mathrm{Ri}=1, \Omega=5$

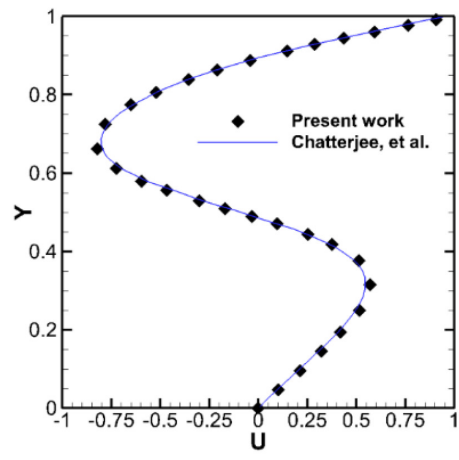

(f) $\mathrm{Ri}=5, \Omega=5$

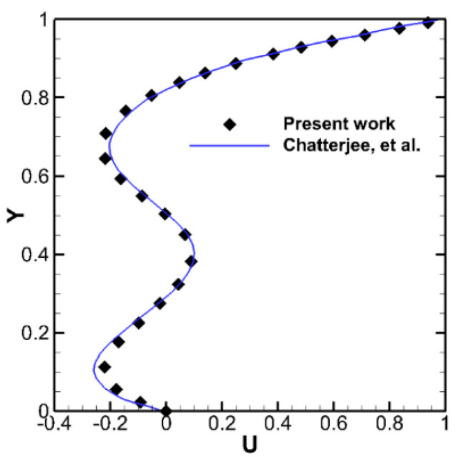

(g) $\mathrm{Ri}=10, \Omega=1$

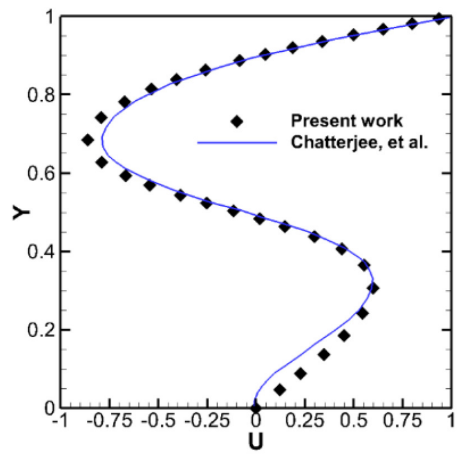

(h) $\mathrm{Ri}=10, \Omega=5$

Fig. 4. Comparison of the present work of the dimensionless velocity profiles along the vertical line at $\mathrm{x}=0.25$ with Chatterjee, et al. [21]. 


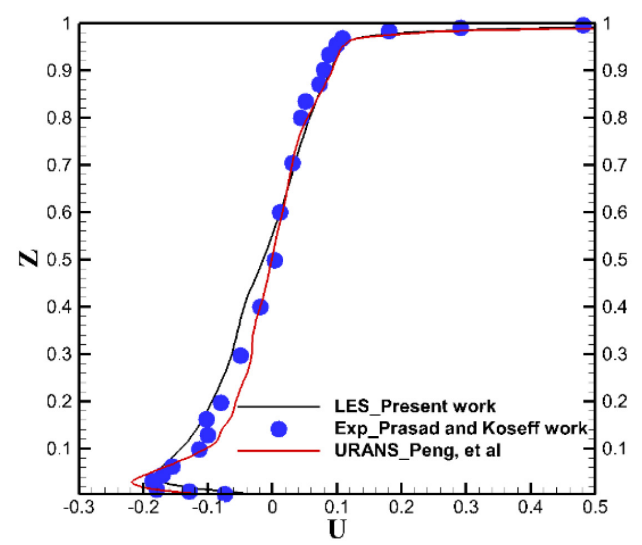

(a) Left velocity

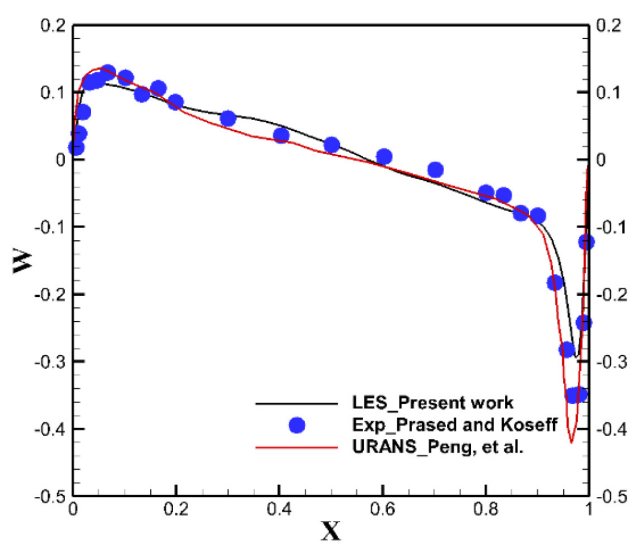

(b) Right velocity

Fig. 5. Mean velocity profiles comparison of the current LES work with Prasad and Koseff [40] and Peng, et al. [41] at $\operatorname{Re}=10000$.

\subsection{RANS model}

224 The Reynolds-averaged Navier-Stokes equations are known as the time-averaged equations of 225 movement for the fluid flow. This section is completed by using the RANS method to study the 226 flow and thermal fields and velocity distribution in a 2D lid-driven enclosure that contains a rotating circular cylinder.

\subsubsection{Flow and thermal fields}

229 Isotherms and streamlines contours are plotted in Fig. 6 at various controlling parameters, 230 Reynolds numbers, $\mathrm{Re}=5000,10000,15000$ and 30000, and rotational speeds, $\Omega=0,1,5$ and 231 10. These contours arise by the coupled impacts of forced shear flow (rotating cylinder and 232 moving top wall forces) besides the buoyancy flow due to the heat differences between the top 233 and bottom walls. It can be observed that the influences of both forced actions are dominated 234 on most of the heat distribution and flow patterns within the enclosure, aside from the minor 235 effect of the driven buoyancy. Substantially, the shear layers are generated nearby the moving objects and their magnitudes totally depend on the values of the speed of the rotating cylinder and the moving top wall.

238 At all values of the Reynolds number and when the inner cylinder is stationary $(\Omega=0)$, the flow

239 field patterns are the consequence of the moving-lid movement and the temperature differences.

240 A clockwise rotating primary eddy, which is formed as a result of the movement of the lid, is 241 encased in most of the cavity besides four small secondary eddies which are placed at the 
242 bottom wall corners (anti-clockwise), the top of the left wall (anti-clockwise) and the right top 243 of the cylinder (clockwise). It can be observed that increasing Reynolds number leads to 244 decreasing the secondary eddies sizes.

245 Whilst the inner cylinder is rotating at low velocity value, $\Omega=1$, the flow field's evolution 246 results from the combined action of the lid-driven movement, the rotating cylinder motion and 247 the buoyancy driven effect. Although some shear layers appear thereabout the inner cylinder at 248 all Reynolds number values, the domination of the main eddy, which is formed by the linear 249 movement of the top wall, covers most of the enclosure regions. However, the influence by the 250 movement of the rotating cylinder is increased by using high values of rotational speed, $\Omega=5$ 251 and $\Omega=10$. Consequently, it can be seen that the effect of the linear movement of the top wall 252 appears as two clockwise vortices and adjacent to the top surface of the cavity. In addition, the 253 two anti-clockwise eddies nearby the bottom walls became clockwise when the rotating speed 254 controls most of the enclosure zones.

255 In general, an increment in linear speed of the lid-driven or in rotation speed of the inner 256 cylinder provides better temperature distribution in the domain, and more particularly when 257 both speeds are high $(\operatorname{Re}=30000$ and $\Omega=10)$.
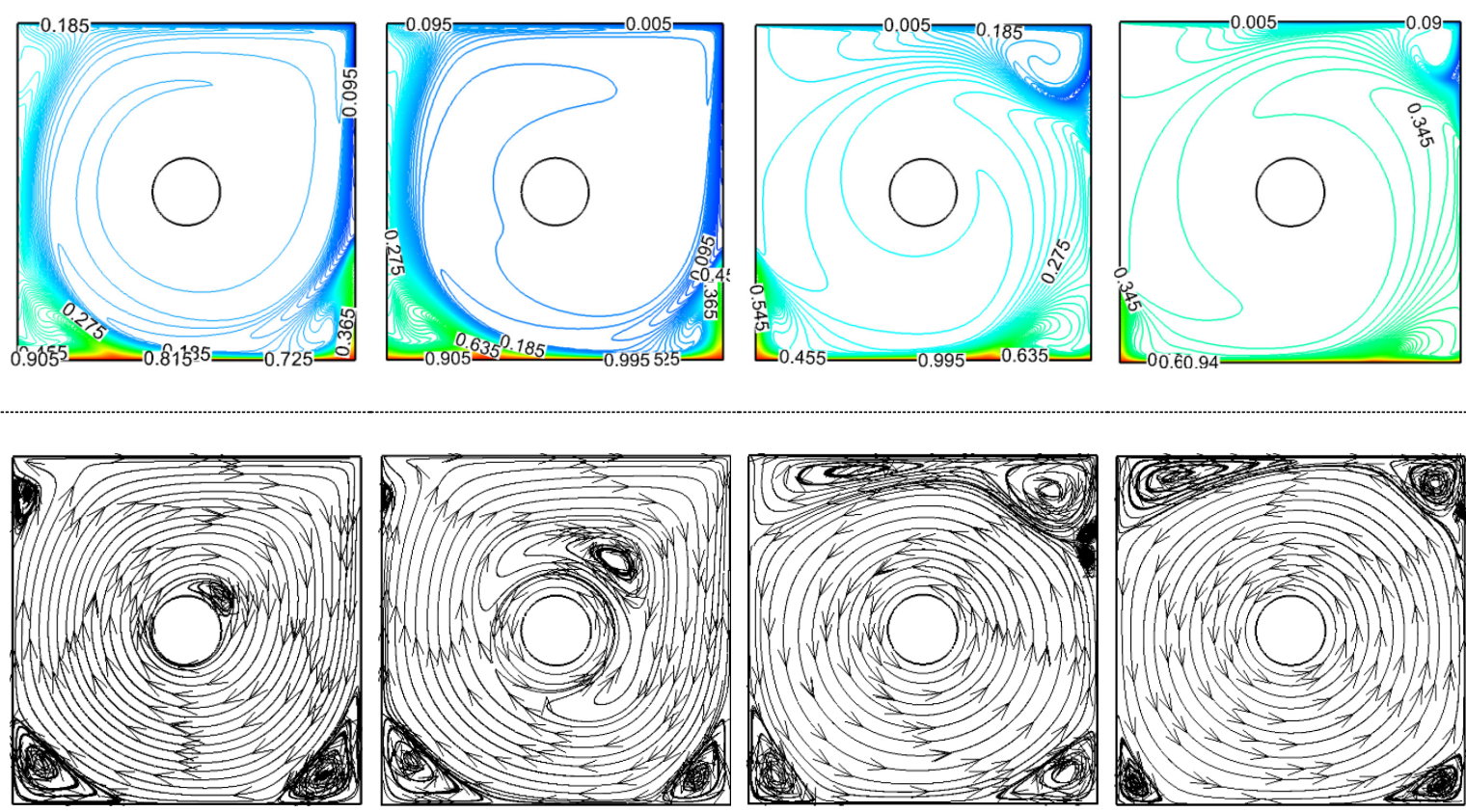

$$
\Omega=0
$$$$
\Omega=1
$$$$
\Omega=5
$$$$
\Omega=10
$$

(a) $\operatorname{Re}=5000$ 

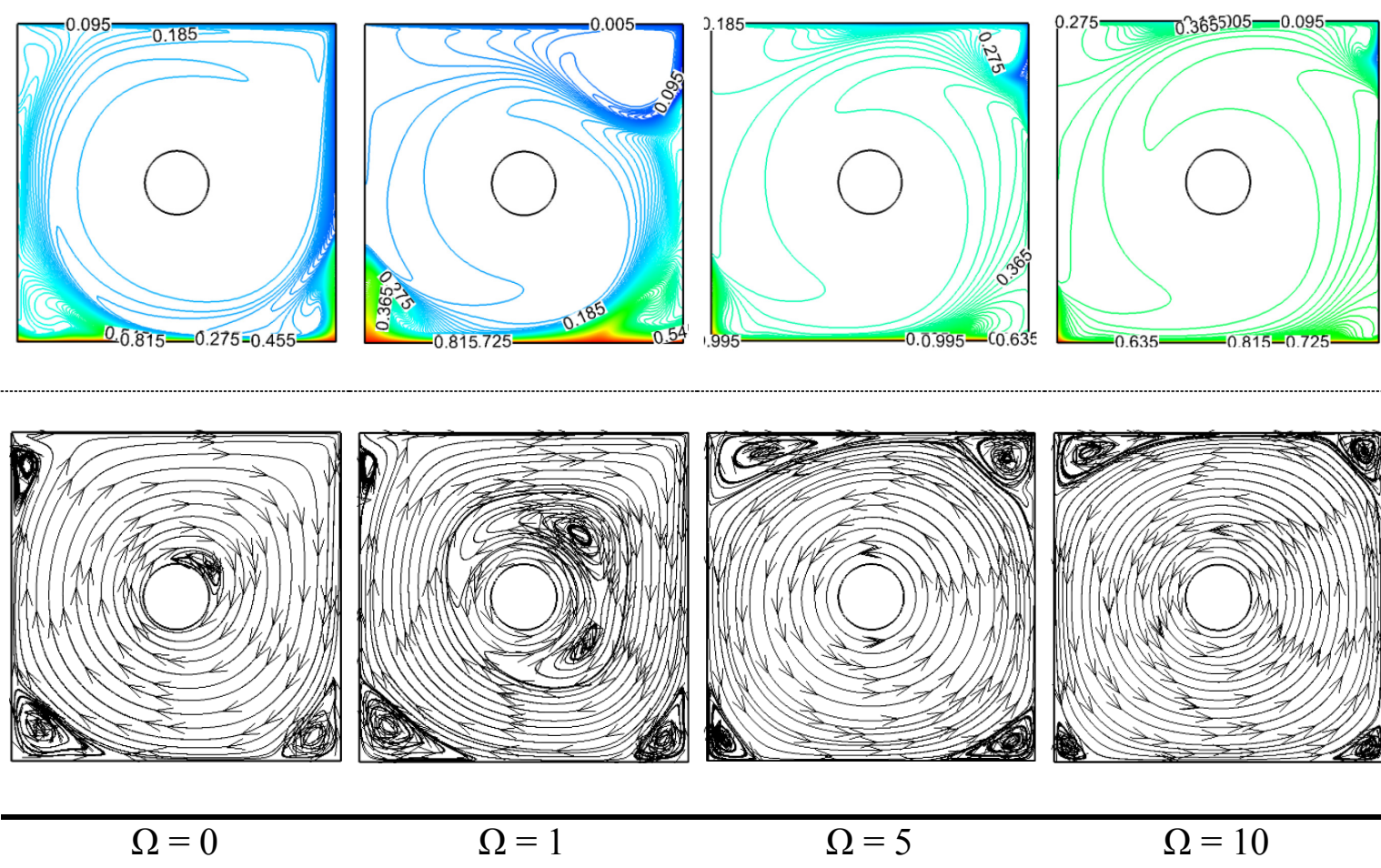

$\Omega=5$

$\Omega=10$

(b) $\operatorname{Re}=10000$
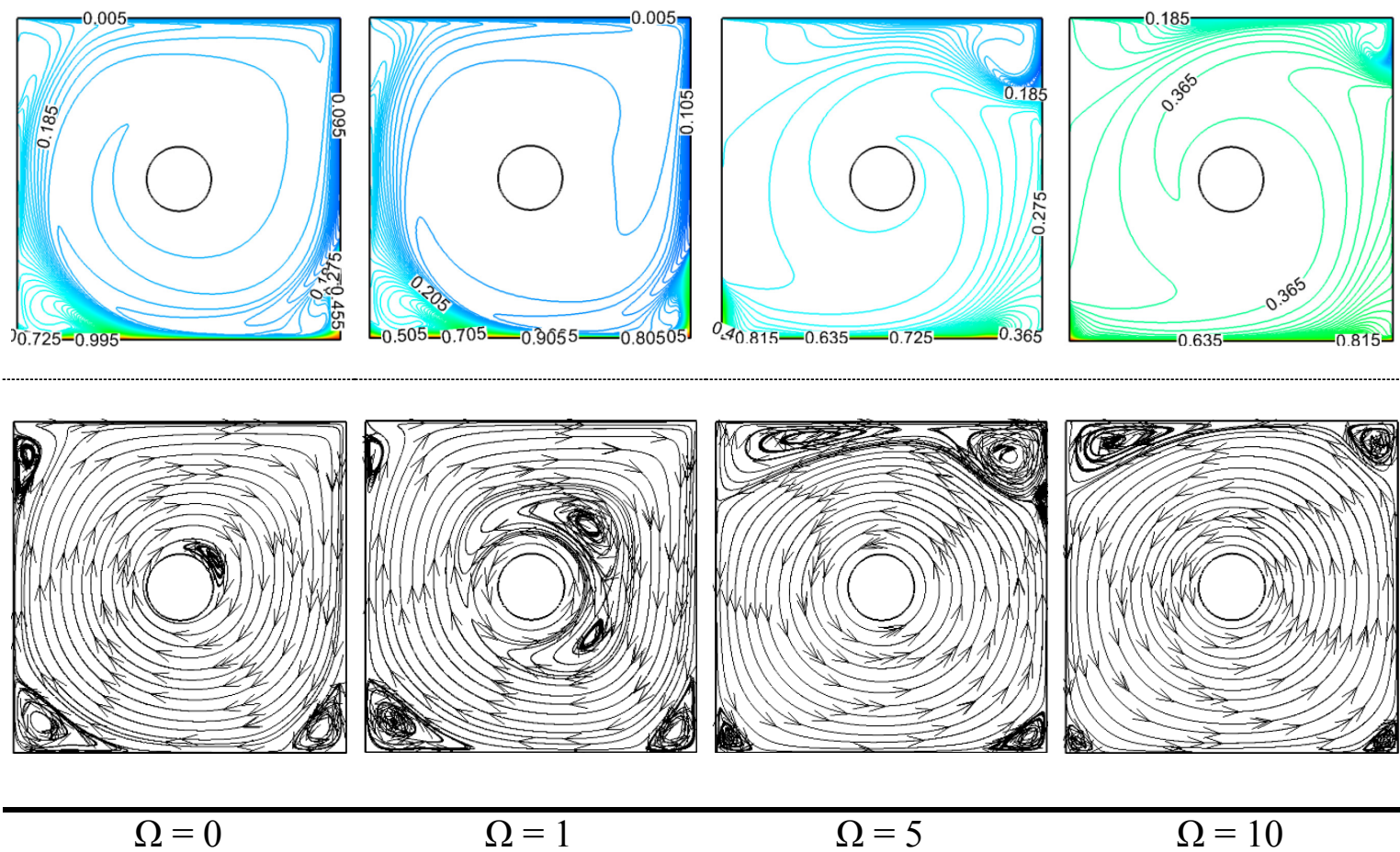

$\Omega=5$

$\Omega=10$

(c) $\operatorname{Re}=15000$ 

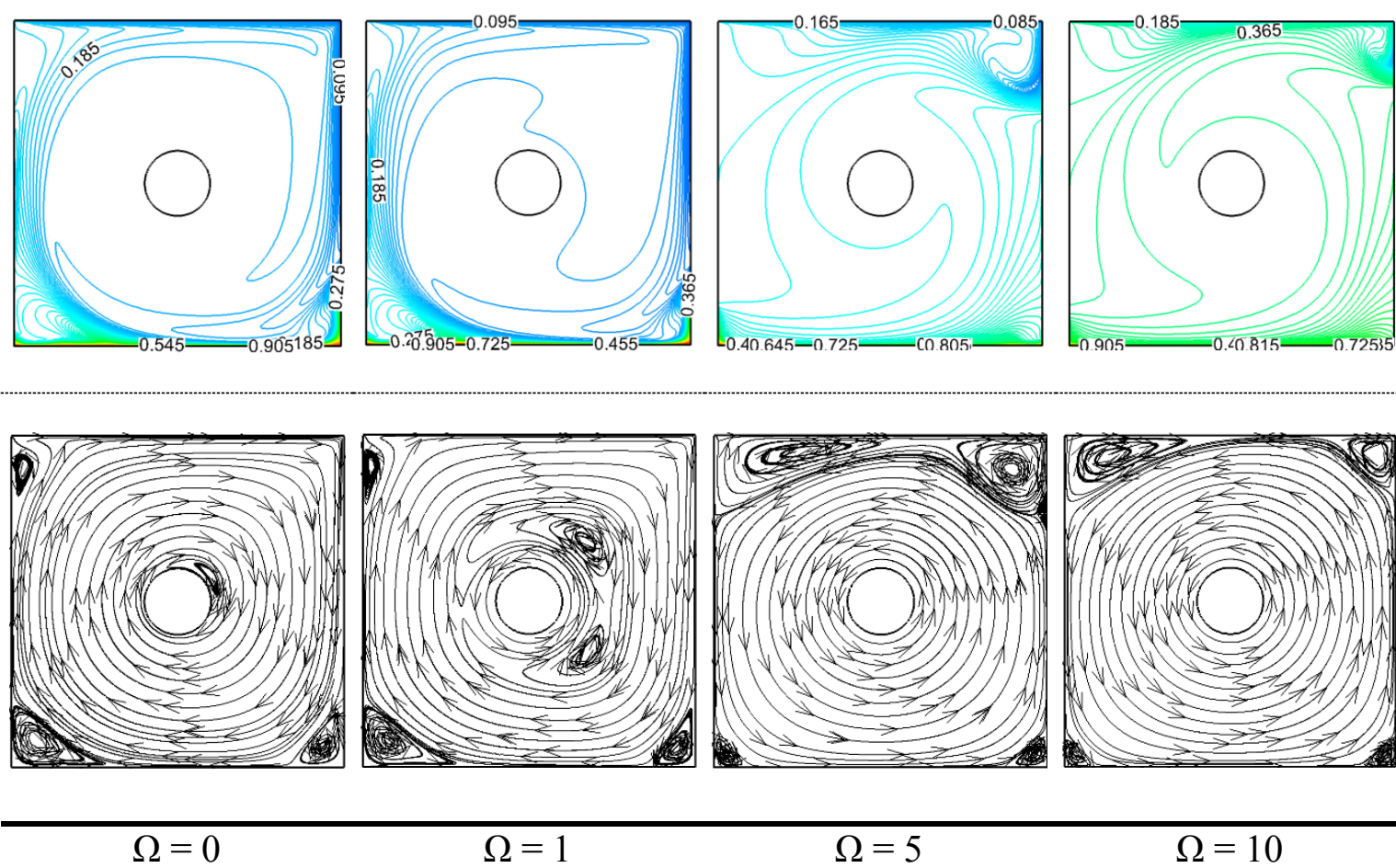

(d) $\operatorname{Re}=30000$

Fig. 6. Isotherms and streamlines contours for different Reynolds numbers and rotating speeds. 


\subsubsection{Velocity distribution}

262 The curves of the dimensionless horizontal velocity distribution along the vertical line, that is 263 located at $(0.25,0,0)$ and $(0.25,1,0)$, for various values of the Reynolds number, $\mathrm{Re}=5000$ 26430000 , and rotational velocity, $\Omega=0-10$, are presented in Fig. 7. Slight differences can be 265 figured out when the rotational speed is equal to zero or one, unlike when the rotating cylinder 266 dominates the flow patterns at high $\Omega$ values. Moreover, it can be concluded that Reynolds 267 number can change the values of the velocity distribution, while the rotating cylinder is holding 268 the direction of the flow in the cavity.

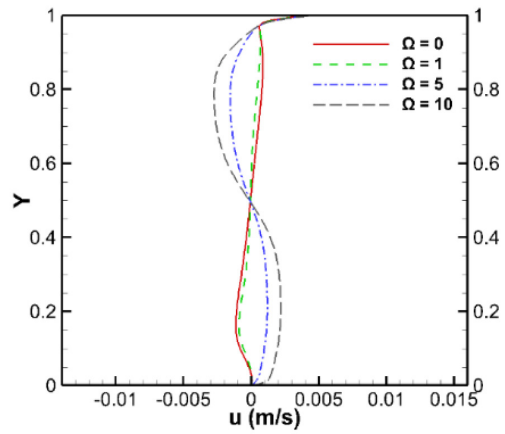

(a) $\operatorname{Re}=5000$

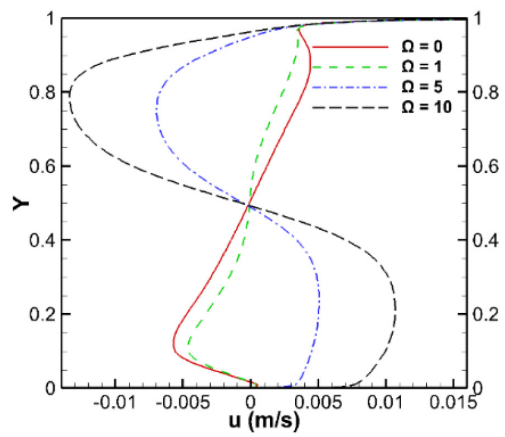

(d) $\mathrm{Re}=30000$

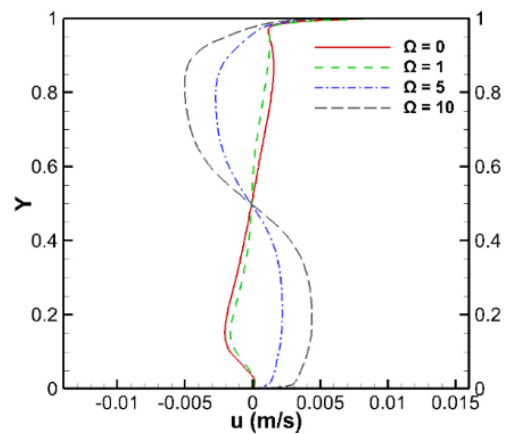

(b) $\mathrm{Re}=10000$

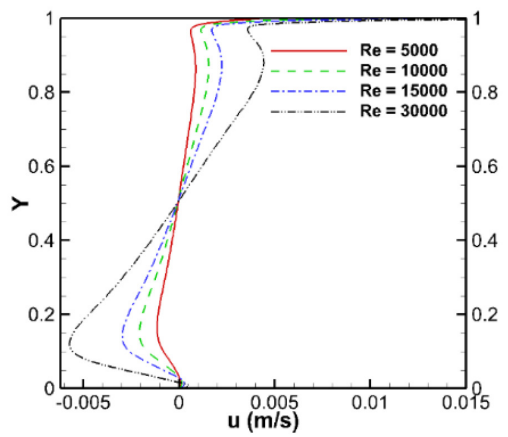

(e) $\Omega=0$

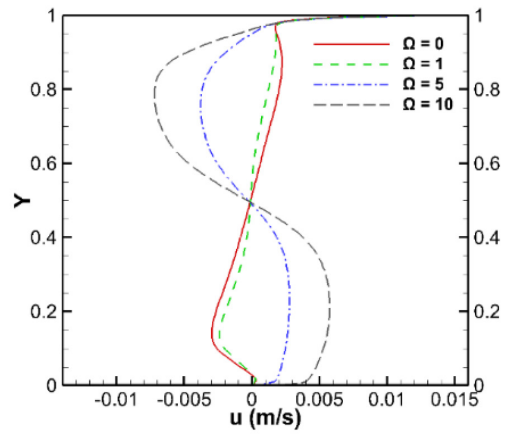

(c) $\mathrm{Re}=15000$

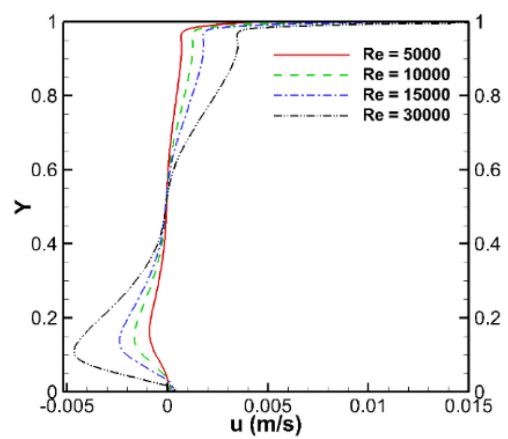

(f) $\Omega=1$

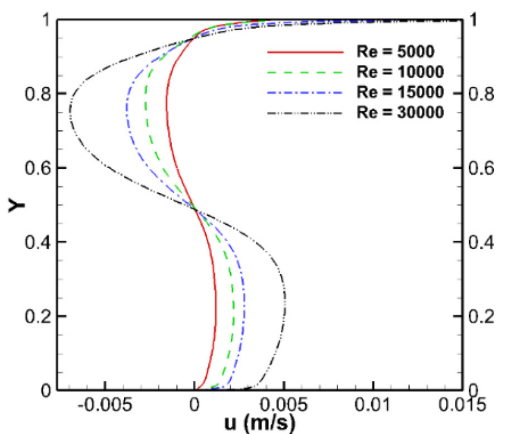

(g) $\Omega=5$

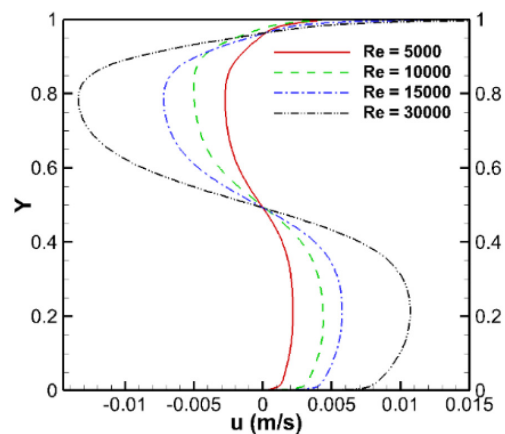

(h) $\Omega=10$

Fig. 7. Velocity distribution along the vertical line for different Reynolds numbers and rotational speeds. 
271 The Unsteady Reynolds-averaged Navier-Stokes equations depend on the time-averaged 272 equations of movement for the fluid flow. However, their mean flow quantities keep changing 273 with time step. This section is completed by using the URANS method to investigate the heat 274 transfer characteristics and Nusselt number in a 3D lid-driven enclosure containing a rotating 275 circular cylinder.

\section{$276 \quad 3.4 .1 \quad$ Heat transfer characteristics}

277 Fig. 8 illustrates the influences of varying rotational speeds of the cylinder, $\Omega=0,1,5$ and 278 Reynolds numbers, $\mathrm{Re}=5000,10000$ and 15000, on three-dimensional profiles of the isotherms 279 and its iso-surface temperatures for the nine cases studies of the cavity in order to understand 280 the flow patterns and the related heat distribution. It can be observed that when the 281 dimensionless rotational velocity is stationary, $\Omega=0$, the top moving wall is controlling all the 282 fluid behaviours and the heat transfer distribution besides the limited buoyancy effect due to 283 the different temperatures of the top and bottom walls. It can be noticed that the flow direction 284 is clockwise. However, when the cylinder is moving in rotational direction at rotating speed 285 equal to one, it can be argued that the rotating force controls the region around the cylinder 286 whereas most of the area of the enclosure is driven by the moving top wall. By comparison to 287 the rotating speed equal to five, this measure shows that most of the cavity's area is covered by 288 the affected flow due to the rotating cylinder's force. Nonetheless, in both cases $(\Omega=1$ and 5$)$ 289 it can be seen that the homogeneity of the temperature division inside the domain is higher than 290 that in the stationary cylinder case. 


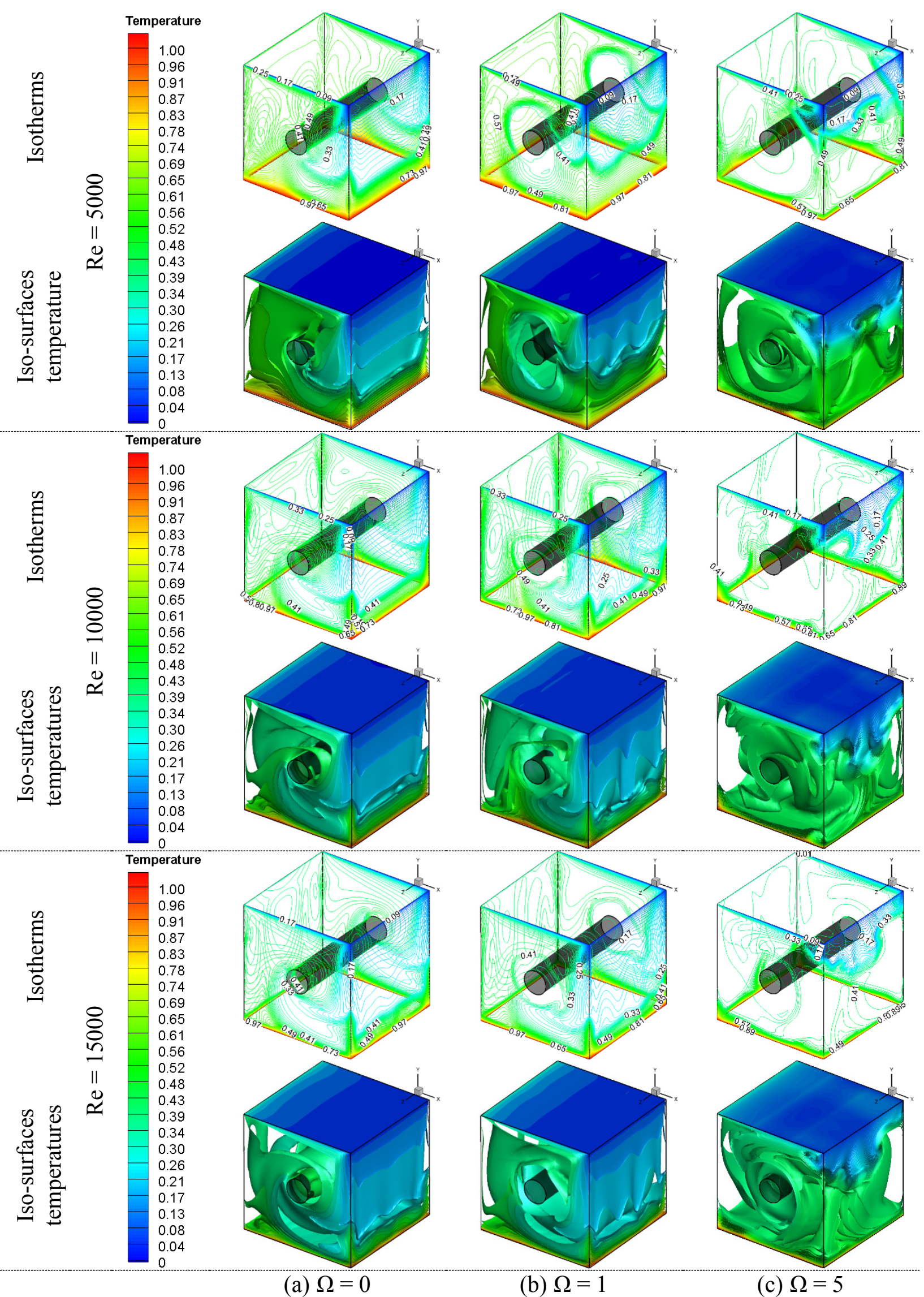

Fig. 8. Three-dimensional isotherms and iso-surfaces temperatures at different Reynolds numbers and rotational speeds. 


\subsubsection{Nusselt number}

293 Fig. 9 shows the average Nusselt number for the chosen values of rotational speed, $\Omega=0,1$ 294 and 10, and Reynolds number, $\operatorname{Re}=5000,10000$ and15000, at the midline of the bottom wall. 295 The Standard k- $\varepsilon$ viscous model with time dependence is exercised in this investigation. 296 Essentially, the figure illustrates that increasing either Re or $\Omega$ values leads to a remarkable 297 enhancement in the average Nusselt number which is mainly the consequences of the increased 298 flow velocity. Since higher motion of the fluid occurs at higher Reynolds number and rotation speed, it can be concluded that the highest Nusselt number occurs when Reynolds number $300=15000$ and the rotational speed $=10$.

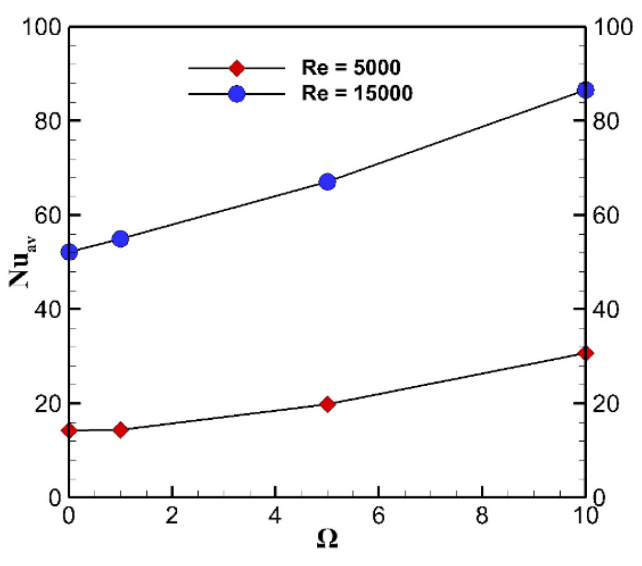

(a) Rotation speeds

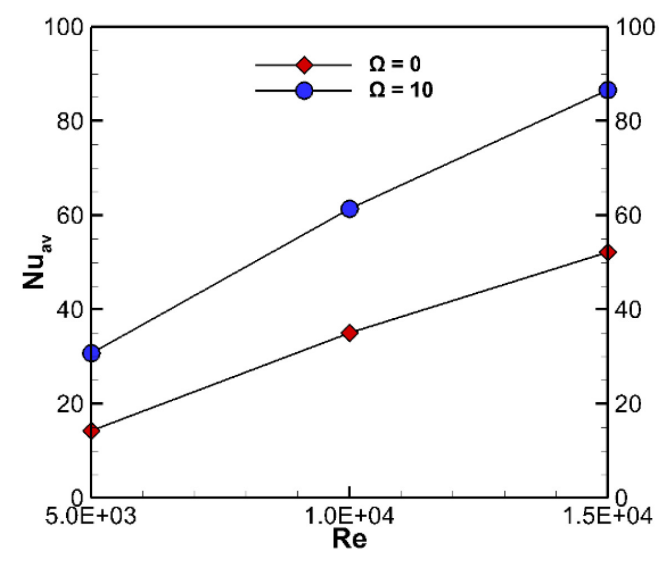

(b) Reynolds numbers

Fig. 9. Average Nusselt number distributions at the bottom wall for different

301

302

303

304

305

306

307

308

309

The local Nusselt number distributions along the midline of the heated top wall $(0,1,0.5$ and 1, 1, 0.5) are shown in Fig. 10 for various values of the rotational speed and Reynolds number. Essentially, it demonstrates that Reynolds number has a meaningful effect on the top wall local Nusselt number for all the cylinder rotational speeds. On the other hand, at rotational speed, 0 $\leq \Omega \leq 5$, and at all Reynolds number values, $R e=5000-15000$, it can be noticed that by changing the rotational speed no distinct change has been detected on the top moving wall local Nusselt number. This can be clarified as the consequences of the strong domination of the liddriven motion on the heat transfer of the top wall. However, when the rotational speed is equal to 10 , it can be observed the clear influences of the rotating cylinder on the top wall heat transfer. These influences increase gradually as increasing Reynolds number. 


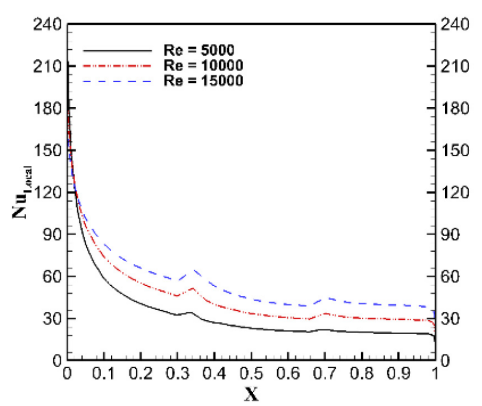

(a) $\Omega=0$

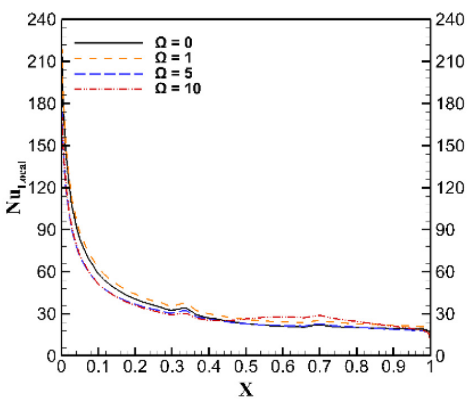

(d) $\operatorname{Re}=5000$

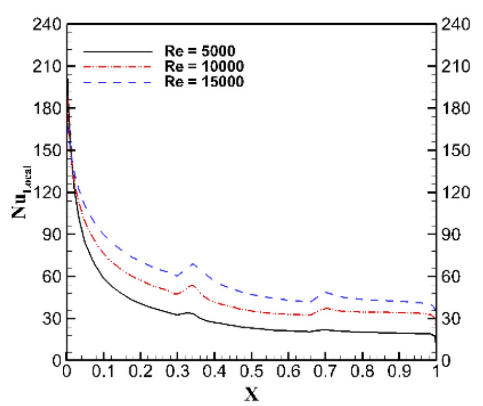

(b) $\Omega=1$

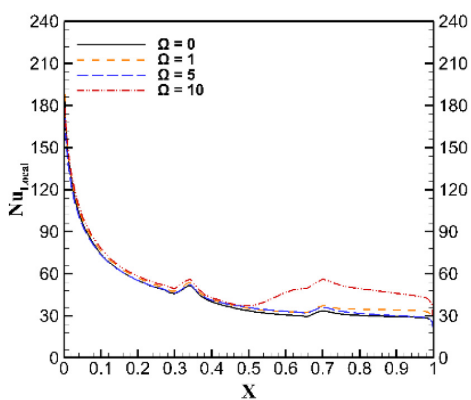

(e) $\operatorname{Re}=10000$

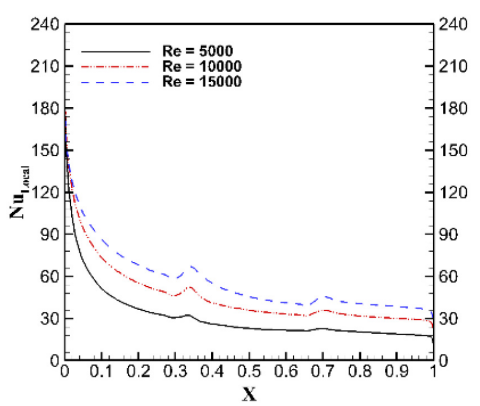

(c) $\Omega=5$

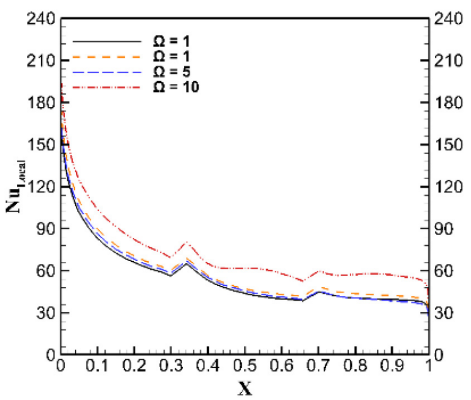

(f) $\operatorname{Re}=15000$

Fig. 10. Local Nusselt number of the top moving wall for different Reynolds numbers and rotational cylinder speeds.

\subsection{Comparison between URANS and LES}

316 Hereinafter, inclusive comparison and discussion will be focused on the findings generated

317 from simulating the unsteady turbulent flow of combined convection heat transfer in the liddriven cavity containing rotating circular cylinder by involving the WALE sub-grid scale model of the LES method and the standard k- $\varepsilon$ model of the URANS method. The simulations are completed for two Reynolds numbers, $\mathrm{Re}=5000$ and 10000, and three rotational speeds, $\Omega=$

3210,1 and 5 . The outcomes and comparisons are presented in terms of velocity vectors, isotherms, 322 iso-surfaces temperatures and local Nusselt numbers. The spectral density profiles of the velocity magnitude at five selected points within the domain in order to confirm the LES

324 simulations are correctly performed are shown in Fig. 11 for $\operatorname{Re}=10000$ and $\Omega=1$. It can be 325 noticed that the slope of $-5 / 3$ in the inertial subrange is observed, showing that the present simulations can be regarded as having the features of a fully turbulent flow. In addition, the results of the LES method are accepted only after reaching the fully developed flow state. Fig.

32812 illustrates the $U_{\text {rms }}$ profile evolution along a line located in the cavity at $(0.25,1,0.5)$ and $329(0.25,0,0.5)$ for different simulation times. It can be seen that after 45 seconds, the flow reaches 330 the steady state. However, the statistical simulations results are collected after 50 seconds to 331 ensure their high quality. 


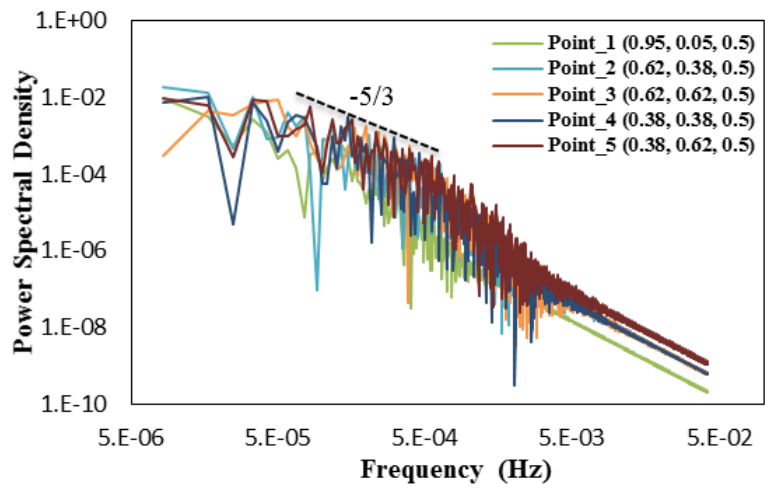

333 Fig. 11. Spectral analysis of velocity magnitude at selected locations for $\operatorname{Re}=10000, \Omega=1$.

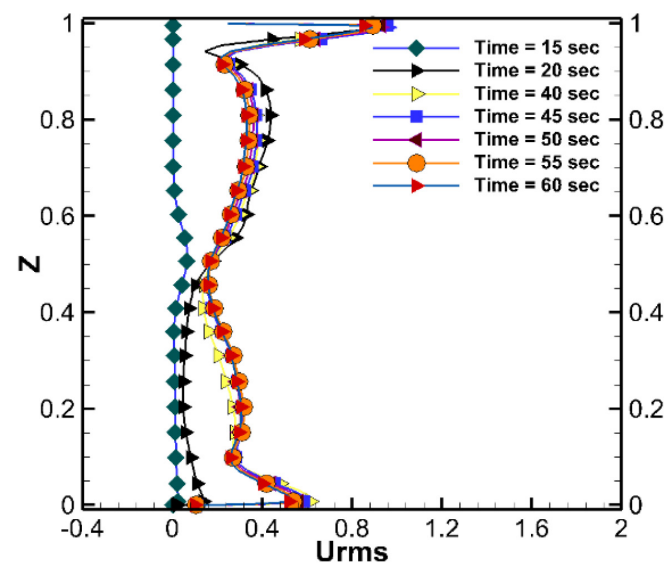

335 Fig. 12. Root mean square velocity profiles at different simulation times

\subsubsection{Three-dimensional isotherms and iso-surface temperatures}

337 The computational results from the LES and URANS methods are compared at chosen

338 rotational speeds of the circular cylinder, $\Omega=0,1$ and 5, and Reynolds numbers, $\operatorname{Re}=5000$.

339 The three-dimensional isotherms and iso-surfaces temperatures are offered in Fig. 13 to analyse

340 the differences between the LES and URANS behaviours. Generally, for stationary cylinder it

341 can be argued that the moving top wall is controlling the flow patterns and the heat transfer.

342 However, for $\Omega=1$, it can be noticed that the force that comes from the rotational cylinder

343 starts influencing the central part of the enclosure. This influence is growing strongly when the

344 rotational speed reaches five. Hence, increasing the rotational speed enhances significantly the

345 heat transfer distribution.

346 In comparison of the turbulent prediction approaches, it can be pointed out from the shown

347 figure that both methods have demonstrated a good ability of showing the primary vortices of

348 the flow for all cases shown in Fig. 13. However, the secondary vortices appear clearly by using 

rotational speed.
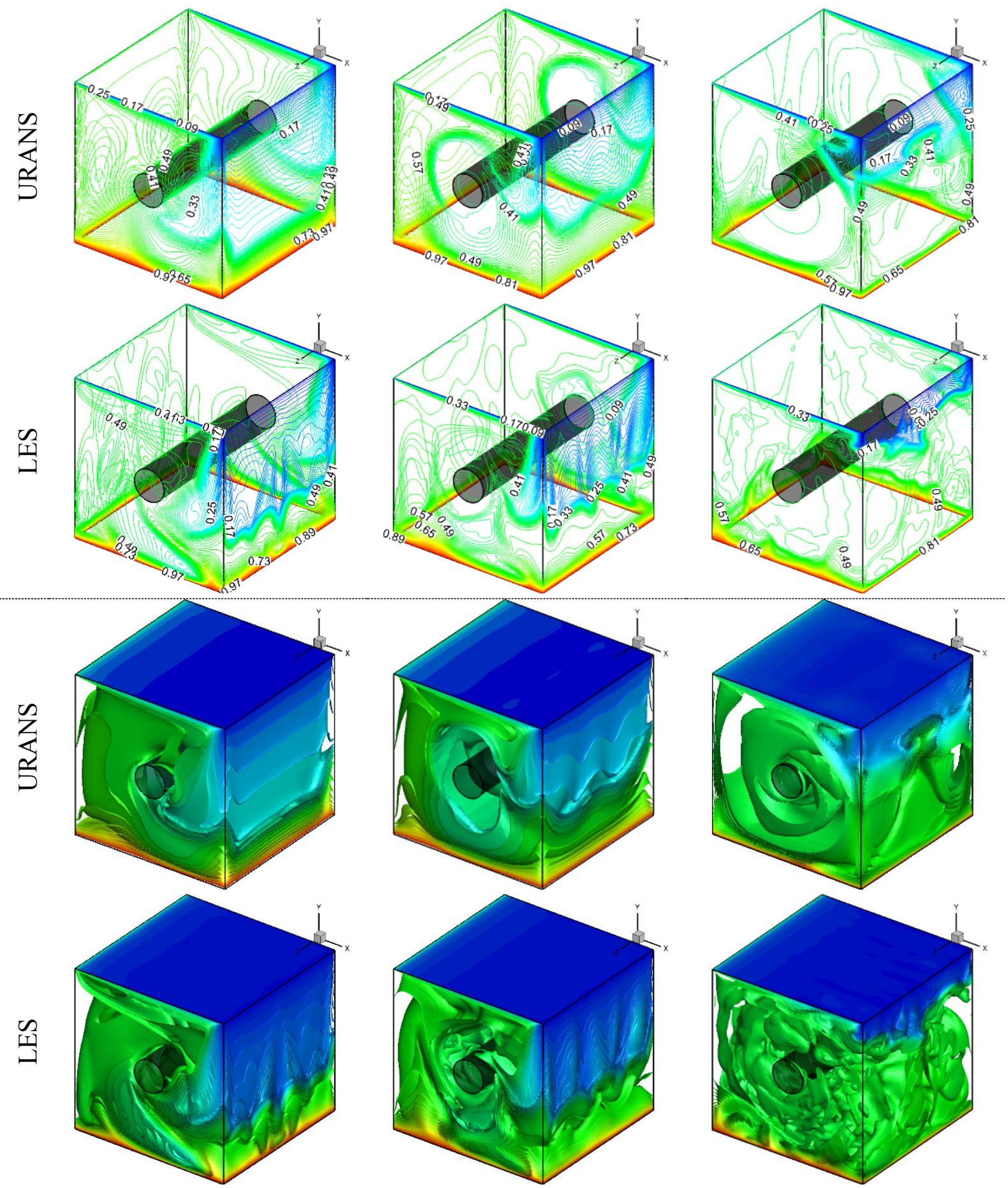

Temprature scale bar

$\begin{array}{llllllllllllllllll}0.01 & 0.07 & 0.13 & 0.19 & 0.25 & 0.31 & 0.37 & 0.43 & 0.49 & 0.55 & 0.61 & 0.67 & 0.73 & 0.79 & 0.85 & 0.91 & 0.97\end{array}$
(a) $\Omega=0$
(b) $\Omega=1$
(c) $\Omega=5$

Fig. 13. Three-dimensional isotherms and iso- surfaces temperatures distribution comparison of URANS and LES at $\mathrm{Re}=5000$. 
354 The flow vectors of both URANS and LES methods have been investigated for Reynolds 355 number, $\operatorname{Re}=5000$, and rotating speed, $\Omega=0,1$ and 5. Fig. 14a illustrates the flow behaviours 356 for the y-z plane located in the middle of the z-axis, and Fig. 14b states the $x-y$ plane located in 357 the midway of the $\mathrm{x}$-axis. Generally, for both approaches and when the circular cylinder is 358 stationary, it can be noticed that the controlling influence of forced convection is due to the 359 moving top wall, especially for the layers nearby the lid-driven wall. The flow nearby the lid360 driven wall is drawn due to the shear force and it impinges onto the motionless-walls. The 361 primary vortex (rotating clockwise) covering the domain centre is distinctly seen in Fig. 14b 362 and this vortex controls most of the flow patterns, as predicted by either URANS or LES 363 method. Further, the displayed vectors in Fig. 14 reveal the presence of the secondary vortices 364 thereabout the domain corners and the top right of the cylinder. However, it can be observed 365 distinctly that the secondary vortices become more visible from the LES prediction for both 366 selected planes, especially when increasing the rotational speed of the cylinder.

367 The superiority of the LES method over the RANS modelling is clearly demonstrated in Figs. 36813 and 14 in capturing more detailed secondary eddies, which reflects the fundamental 369 difference of the two approaches. Essentially the RANS approach uses the time averaging 370 procedure to obtain the Reynolds averaged transport equations for the mean flow quantities and 371 all scales (both large and small) of turbulence are represented by a model such as the standard $372 \mathrm{k}-\varepsilon$ model adapted in this paper. In contrast the LES approach employs the space filtering 373 procedure to derive the transport equations for both the mean flow quantities and the large 374 scales of turbulence, and only the smaller scale eddies that cannot be resolved by the 375 computational grid are modelled by a SGS model such as the WALE model used in the 376 comparison. 

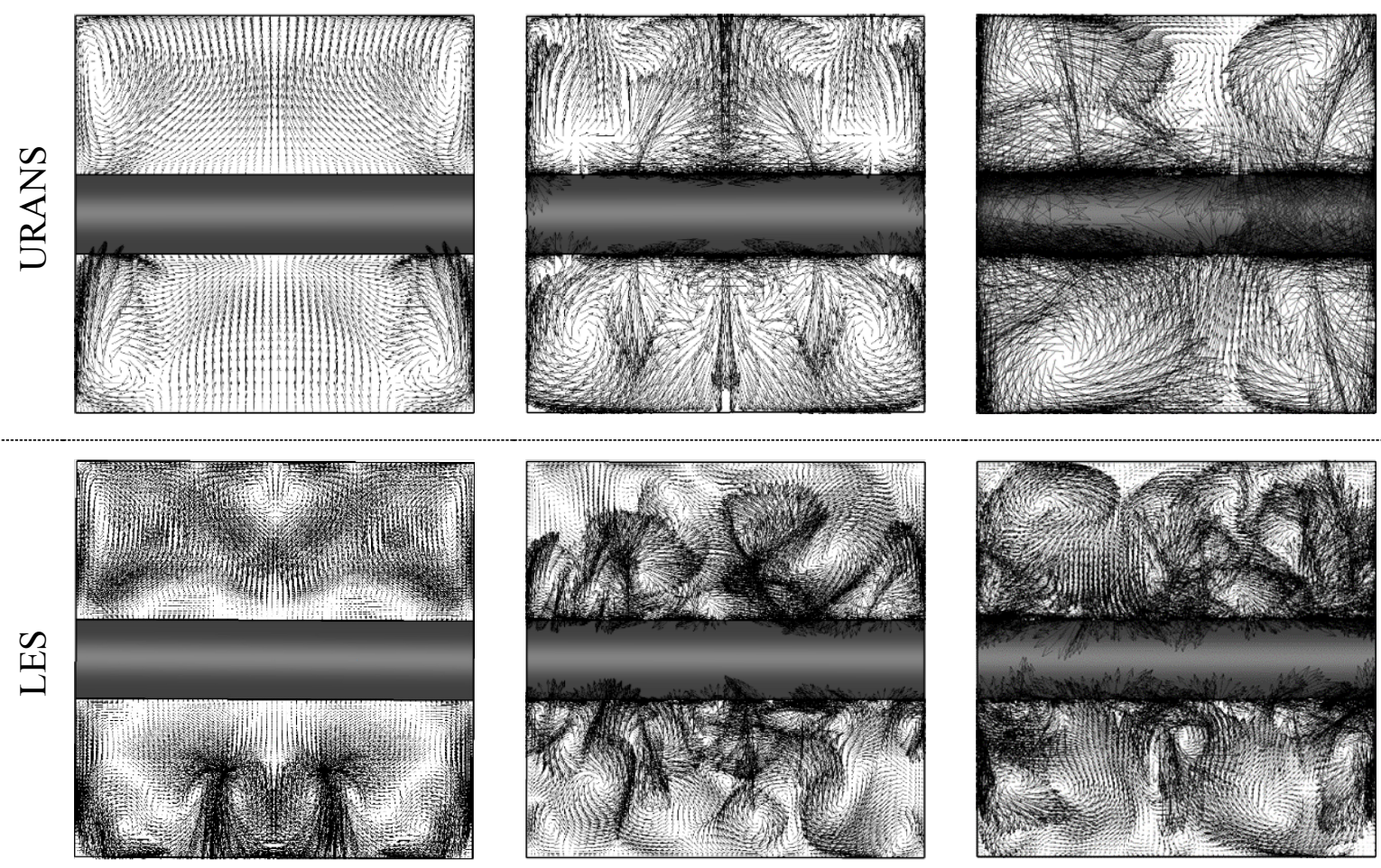

$$
\Omega=0
$$

$$
\Omega=1
$$$$
\Omega=5
$$

(a) y-z plane located in the middle of the z-axis
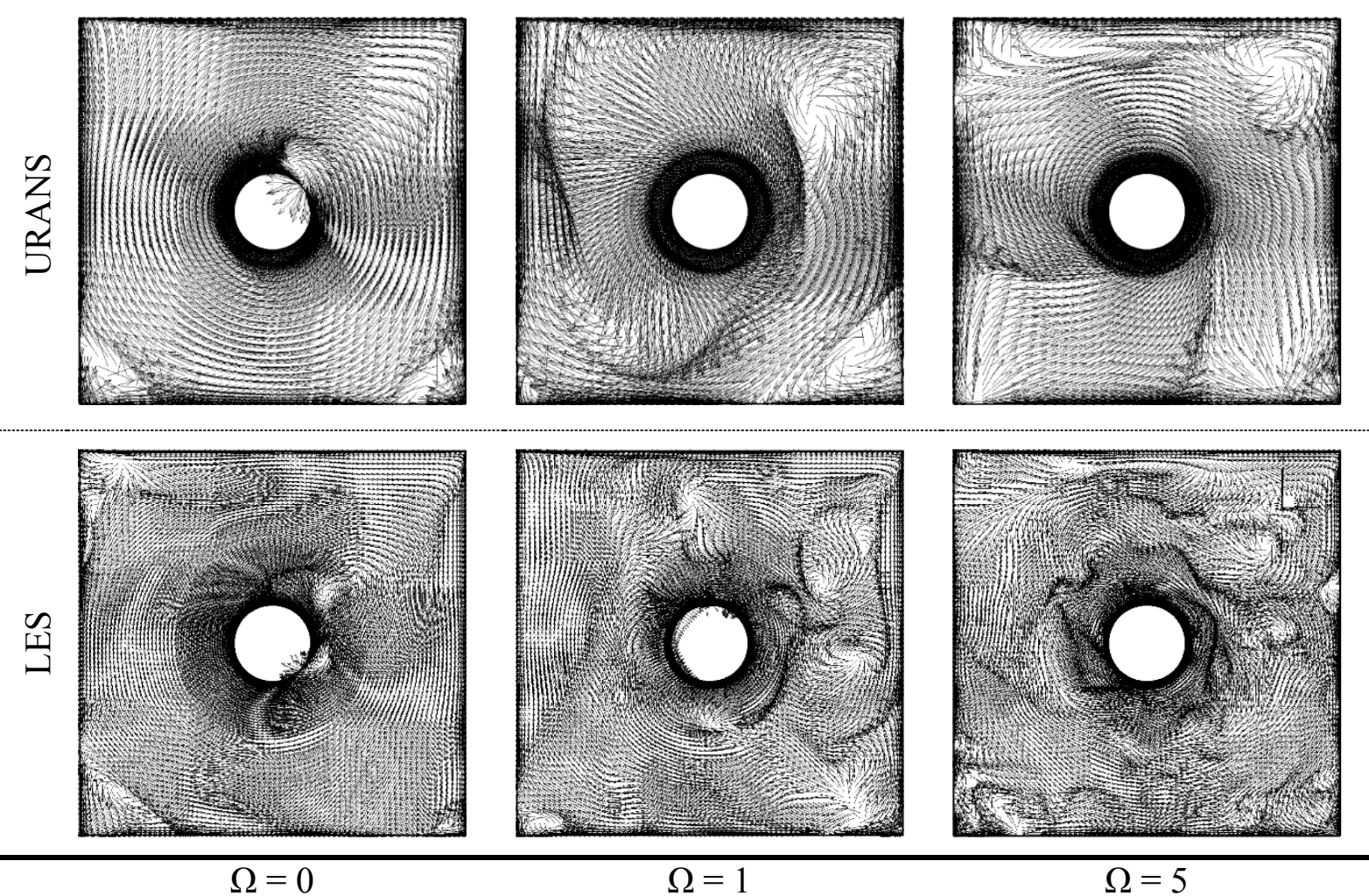

(b) $x$-y plane located in the middle of the z-axis

Fig. 14. Flow vectors comparison between URANS and LES at Re $=5000$. 


\subsubsection{Nusselt number}

378 Fig. 15 illustrates the comparison between the LES and URANS methods in terms of local

379 Nusselt number on the line that is located at the left of the top lid-driven wall $(0,1,0.5$ and $3800.005,1,0.5$ ) for different rotational speeds of the circular cylinder, $0 \leq \Omega \leq 5$, and at $\operatorname{Re}=$ 381 10000. For all rotational speeds, it can be clearly noticed that the LES approach shows distinct 382 advantage over the URANS approach in predicting higher heat transfer coefficients in the region that is closer to the moving wall of the cavity, owing to its ability in capturing the contribution from the secondary vortices.

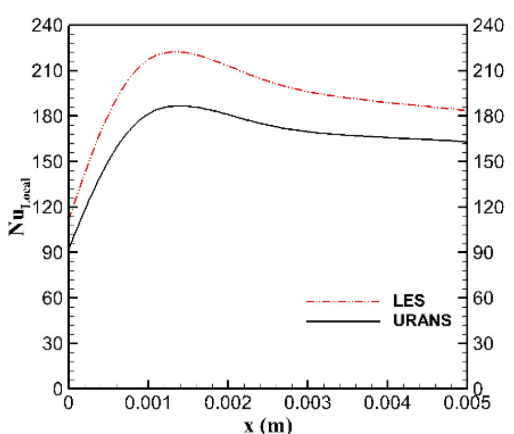

(a) $\Omega=0$

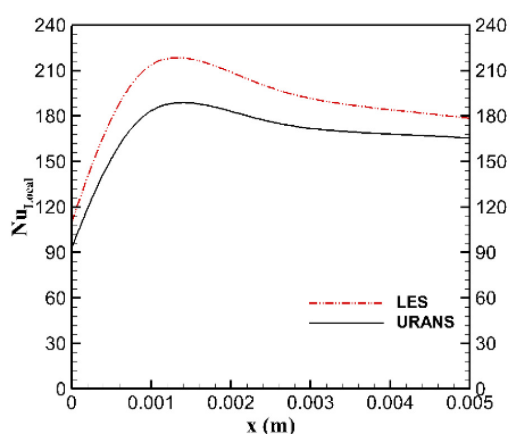

(b) $\Omega=1$

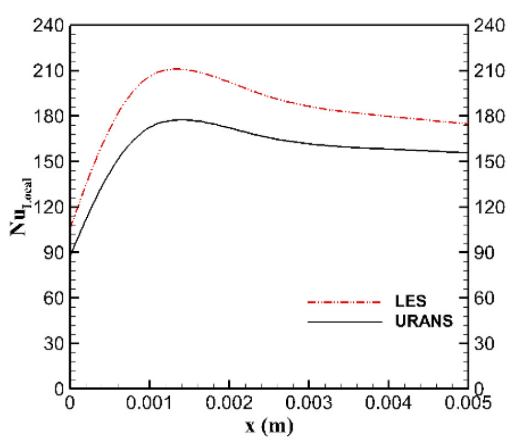

(c) $\Omega=5$

Fig. 15. Comparison of local Nusselt number for different rotational speeds and at $\mathrm{Re}=$ 10000.

\section{Conclusions}

The three-dimensional problem of turbulent flow within the lid-driven cubical enclosure, which is differentially heated and contains a rotating cylinder, has been simulated by using the finite volume method. The influences of various values of both the rotational speed of circular cylinder and Reynolds number are examined, and the striking performances of the URANS and LES approaches are scrutinized. The currently acquired outcomes have revealed interesting behaviours of the turbulent flow and thermal fields in the obstructed enclosure, and the following are the itemized observations from the present research:

- The velocity distributions and flow structures are substantially affected by the Reynolds number and rotational speed of the cylinder. Increasing the rotational speed or the Reynolds number commands to accretion in the average Nusselt number. The highest value of Nusselt number occurs at the highest Reynolds number and rotational speed because of the high increment in the fluid motion.

- For stationary cylinder, $\Omega=0$, the flow is mainly driven by the moving top wall, and is assisted by the buoyancy effect due to the temperature differences between the top and 
bottom walls. The central main eddy (clockwise) controls most of the domain whilst the secondary vortices are shown clearly at the corners of the enclosure, particularly by the LES approach.

- For $\Omega=1$, it is observed that the rotating cylinder has gained control over the regions surrounding the cylinder by creating an eddy that is circumscribed about the proximity of the cylinder. Many secondary vortices appear in this case because of the opposite direction actions by the moving top wall and the rotational cylinder.

- However, when the rotational speed is increased to five, it is noticed that the rotating cylinder dominates more regions than the moving top wall and the buoyancy induced flow. Herein, the primary vortex (anticlockwise) is led by the forced rotational movement and the number of the secondary vortices is increased as a result of the increment in the flow movement.

- For all the Reynolds number values reported here, it is shown that the effects of the rotational speeds, $1 \leq \Omega \leq 10$, are remarkable on the Nusselt number on the cool bottom wall, but their effects on the top moving wall can be neglected unless the rotational speed reaches 10 .

- In all cases of different Reynolds numbers and rotational speeds, it is demonstrated convincingly that the LES method can capture more detailed secondary eddies than the URANS model. Although the LES approach is more demanding in terms of computational time and mesh features, this study has expounded that the LES method has distinct merits over the URANS method in predicting accurately the unsteady flow structures and thermal fields.

\section{Acknowledgements}

424 The authors would like to thank the Ministry of Higher Education and Scientific Research of 425 Iraq for the financial support of the project. 
428 [1] P. Sagaut, Large eddy simulation for incompressible flows: an introduction, Springer 429 Science \& Business Media, 2006.

430 [2] J. Smagorinsky, General circulation experiments with the primitive equations: I. the basic

[3] H. Raiesi, U. Piomelli, A. Pollard, Evaluation of turbulence models using direct numerical and large-eddy simulation data, Journal of Fluids Engineering, 133(2) (2011) 021203.

[4] K. Kim, A.I. Sirviente, R.F. Beck, The complementary RANS equations for the simulation of viscous ows, Int. J. Numer. Meth. Fluids, 48 (2005) 199-229.

[5] L. Liu, J. Li, Z. Feng, A numerical method for simulation of attached cavitation flows, International journal for numerical methods in fluids, 52(6) (2006) 639-658.

[6] R. Henkes, F. Van Der Vlugt, C. Hoogendoorn, Natural-convection flow in a square cavity calculated with low-Reynolds-number turbulence models, International Journal of Heat and Mass Transfer, 34(2) (1991) 377-388.

[7] N. Ben-Cheikh, F. Hammami, A. Campo, B. Ben-Beya, A dynamic sub-grid scale model for large eddy simulation of turbulent flows in a lid-driven cubical cavity, Comptes Rendus Mécanique, 340(10) (2012) 721-730.

[8] S. Ray, D. Chatterjee, MHD mixed convection in a lid-driven cavity including heat conducting circular solid object and corner heaters with Joule heating, International Communications in Heat and Mass Transfer, 57 (2014) 200-207.

[9] C.-C. Liao, C.-A. Lin, Mixed convection of a heated rotating cylinder in a square enclosure, International Journal of Heat and Mass Transfer, 72 (2014) 9-22.

[10] D. Chatterjee, B. Mondal, P. Halder, Hydromagnetic Mixed Convective Transport in a Vertical Lid-Driven Cavity Including a Heat Conducting Rotating Circular Cylinder, Numerical Heat Transfer, Part A: Applications, 65(1) (2014) 48-65.

[11] S.H. Hussain, A.K. Hussein, Mixed convection heat transfer in a differentially heated square enclosure with a conductive rotating circular cylinder at different vertical locations, International Communications in Heat and Mass Transfer, 38(2) (2011) 263-274.

[12] Y.G. Park, H.S. Yoon, M.Y. Ha, Natural convection in square enclosure with hot and cold cylinders at different vertical locations, International Journal of Heat and Mass Transfer, 55(25) (2012) 7911-7925.

[13] F. Karimi, H.T. Xu, Z. Wang, M. Yang, Y. Zhang, Numerical Simulation of Unsteady Natural Convection from Heated Horizontal Circular Cylinders in a Square Enclosure, Numerical Heat Transfer, Part A: Applications, 65(8) (2014) 715-731.

[14] H.S. Yoon, Y.G. Park, J.H. Jung, Natural Convection in a Square Enclosure with Differentially Heated Two Horizontal Cylinders, Numerical Heat Transfer, Part A: Applications, 65(4) (2014) 302-326.

[15] R. Roslan, H. Saleh, I. Hashim, A. Bataineh, Natural convection in an enclosure containing a sinusoidally heated cylindrical source, International Journal of Heat and Mass Transfer, 70 (2014) 119-127.

[16] C. Choi, S. Jeong, M.Y. Ha, H.S. Yoon, Effect of a circular cylinder's location on natural convection in a rhombus enclosure, International Journal of Heat and Mass Transfer, 77 (2014) 60-73.

[17] M. Billah, M. Rahman, U.M. Sharif, N. Rahim, R. Saidur, M. Hasanuzzaman, Numerical analysis of fluid flow due to mixed convection in a lid-driven cavity having a heated circular hollow cylinder, International Communications in Heat and Mass Transfer, 38(8) (2011) 10931103 .

[18] K. Khanafer, S. Aithal, Laminar mixed convection flow and heat transfer characteristics in a lid driven cavity with a circular cylinder, International Journal of Heat and Mass Transfer, 66 (2013) 200-209. 
[19] A.W. Islam, M.A. Sharif, E.S. Carlson, Mixed convection in a lid driven square cavity with an isothermally heated square blockage inside, International Journal of Heat and Mass Transfer, 55(19) (2012) 5244-5255.

[20] F. Selimefendigil, H.F. Öztop, Numerical study of MHD mixed convection in a nanofluid filled lid driven square enclosure with a rotating cylinder, International Journal of Heat and Mass Transfer, 78 (2014) 741-754.

[21] D. Chatterjee, S.K. Gupta, B. Mondal, Mixed convective transport in a lid-driven cavity containing a nanofluid and a rotating circular cylinder at the center, International Communications in Heat and Mass Transfer, 56 (2014) 71-78.

[22] R. Roslan, H. Saleh, I. Hashim, Effect of rotating cylinder on heat transfer in a square enclosure filled with nanofluids, International Journal of Heat and Mass Transfer, 55(23) (2012) 7247-7256.

[23] V. Costa, A. Raimundo, Steady mixed convection in a differentially heated square enclosure with an active rotating circular cylinder, International Journal of Heat and Mass Transfer, 53(5) (2010) 1208-1219.

[24] M. Mahmoodi, S.M. Sebdani, Natural convection in a square cavity containing a nanofluid and an adiabatic square block at the center, Superlattices and Microstructures, 52(2) (2012) 261-275.

[25] S. Saedodin, M. Biglari, M.H. Esfe, M.J. Noroozi, Mixed convection heat transfer performance in a ventilated inclined cavity containing heated blocks: effect of dispersing $\mathrm{Al} 2 \mathrm{O} 3$ in water and aspect ratio of the block, Journal of Computational and Theoretical Nanoscience, 10(11) (2013) 2663-2675.

[26] S. Aminossadati, B. Ghasemi, Natural convection cooling of a localised heat source at the bottom of a nanofluid-filled enclosure, European Journal of Mechanics-B/Fluids, 28(5) (2009) 630-640.

[27] G.A. Sheikhzadeh, A. Arefmanesh, M. Mahmoodi, Numerical study of natural convection in a differentially-heated rectangular cavity filled with TiO2-water nanofluid, in: Journal of Nano Research, Trans Tech Publ, 2011, pp. 75-80.

[28] K.C. Lin, A. Violi, Natural convection heat transfer of nanofluids in a vertical cavity: Effects of non-uniform particle diameter and temperature on thermal conductivity, International Journal of Heat and Fluid Flow, 31(2) (2010) 236-245.

[29] E. Abu-Nada, Z. Masoud, A. Hijazi, Natural convection heat transfer enhancement in horizontal concentric annuli using nanofluids, International Communications in Heat and Mass Transfer, 35(5) (2008) 657-665.

[30] K. Khanafer, K. Vafai, M. Lightstone, Buoyancy-driven heat transfer enhancement in a two-dimensional enclosure utilizing nanofluids, International Journal of Heat and Mass Transfer, 46(19) (2003) 3639-3653.

[31] S. Hussain, K. Mehmood, M. Sagheer, MHD mixed convection and entropy generation of water-alumina nanofluid flow in a double lid driven cavity with discrete heating, Journal of Magnetism and Magnetic Materials, 419 (2016) 140-155.

[32] S. Hussain, S. Ahmad, K. Mehmood, M. Sagheer, Effects of inclination angle on mixed convective nanofluid flow in a double lid-driven cavity with discrete heat sources, International Journal of Heat and Mass Transfer, 106 (2017) 847-860.

[33] K. Mehmood, S. Hussain, M. Sagheer, Mixed convection in alumina-water nanofluid filled lid-driven square cavity with an isothermally heated square blockage inside with magnetic field effect: Introduction, International Journal of Heat and Mass Transfer, 109 (2017) 397-409.

[34] F.M. White, Fluid mechanics, WCB, ed: McGraw-Hill, Boston, (1999).

[35] H.K. Versteeg, W. Malalasekera, An introduction to computational fluid dynamics: the finite volume method, Pearson Education, 2007. 
526 [36] A.K. Kareem, S. Gao, A.Q. Ahmed, Unsteady simulations of mixed convection heat 527 transfer in a 3D closed lid-driven cavity, International Journal of Heat and Mass Transfer, 100 528 (2016) 121-130.

529 [37] P. Huang, J. Bardina, T. Coakley, Turbulence Modeling Validation, Testing, and 530 Development, NASA Technical Memorandum, 110446 (1997).

531 [38] F. Nicoud, F. Ducros, Subgrid-scale stress modelling based on the square of the velocity gradient tensor, Flow, turbulence and Combustion, 62(3) (1999) 183-200.

533 [39] A. FLUENT, 15.0 Theory Guide, Ansys Inc, 5 (2013).

534 [40] A.K. Prasad, J.R. Koseff, Reynolds number and end-wall effects on a lid-driven cavity 535 flow, Physics of Fluids A: Fluid Dynamics (1989-1993), 1(2) (1989) 208-218.

536 [41] S.-H. Peng, P. Doerffer, W. Haase, Progress in Hybrid RANS-LES Modelling, (2009). 